\title{
Collaboration and Leadership
}

Author: Zaida Chinchilla Rodriguez

Presenter: Dakota Murray

Seminarios del
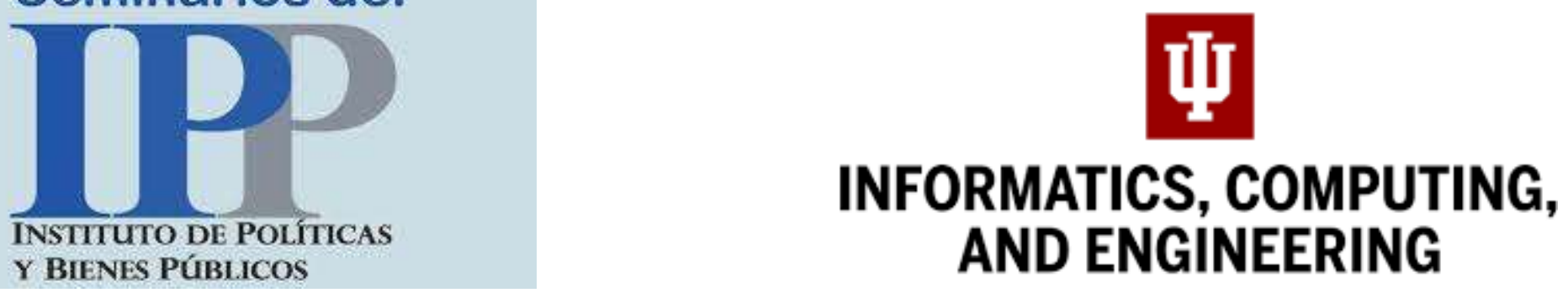


\section{Zaida Chinchilla-Rodríguez}

\section{zaida.chinchilla@csic.es}

Also: Cassidy Sugimoto and Vincent Lariviére

Paper submitted to PLoS One

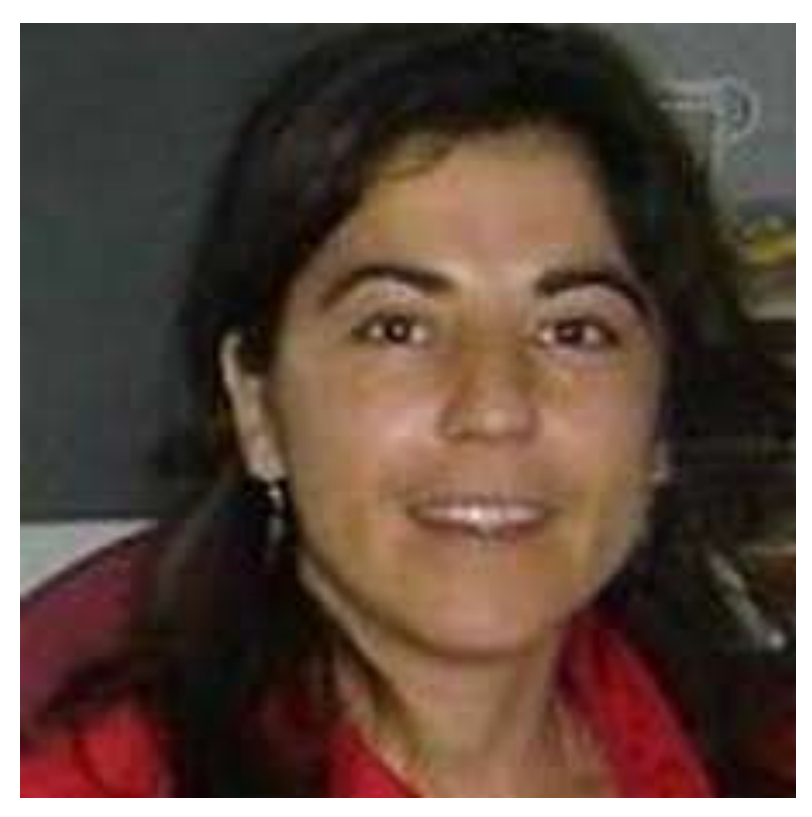

Seminarios del

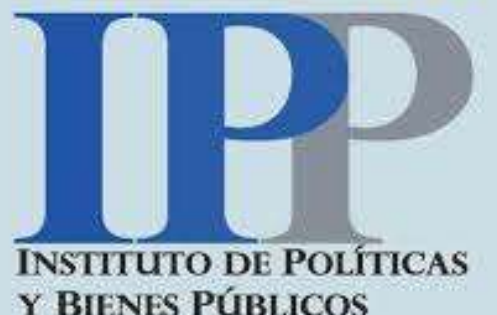




\section{Leadership in science}




\section{The traditional idea of scientific leadership}

- Popular characterizations of (western) scientific history is full of scientific "leaders"
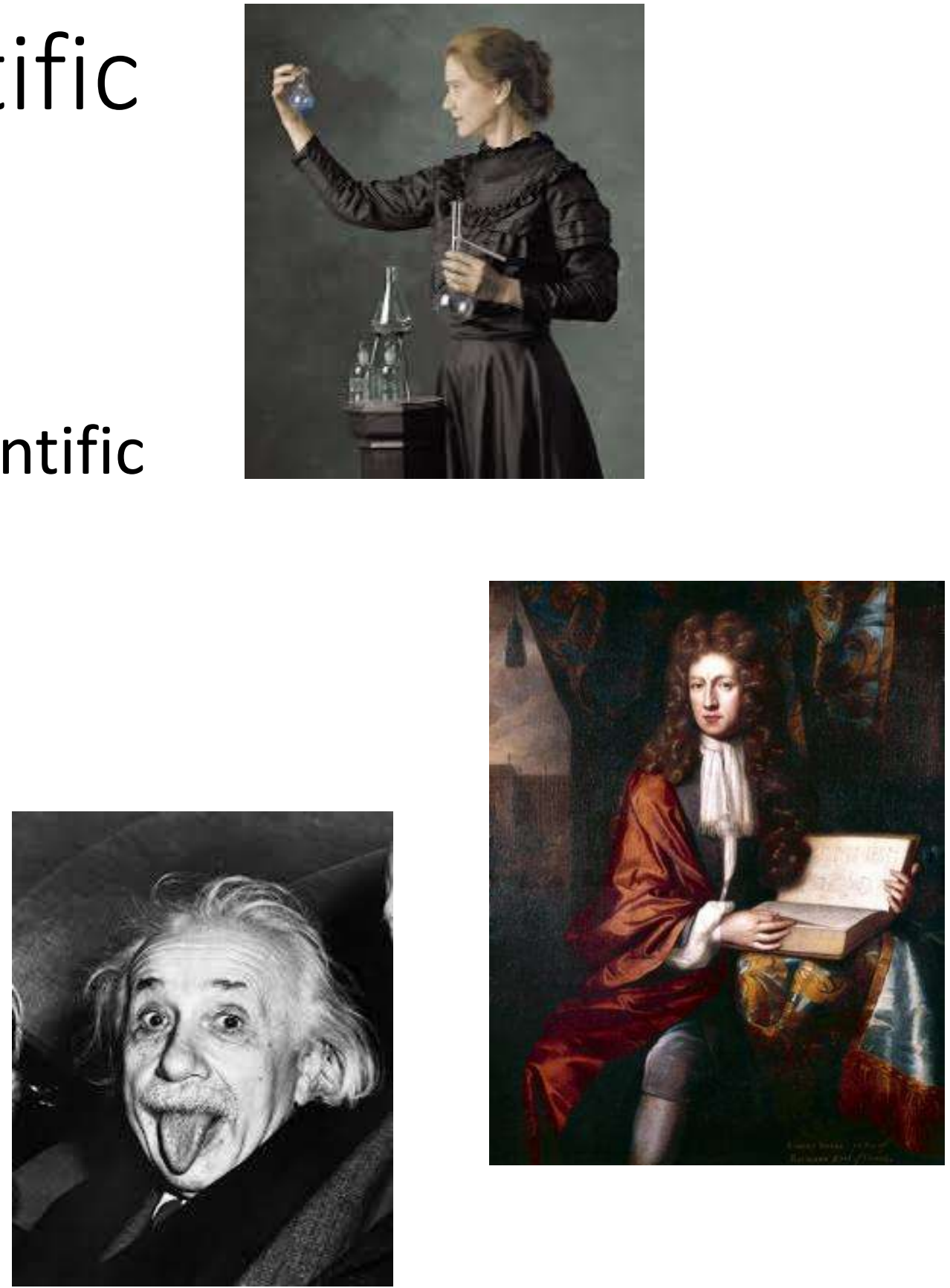


\section{But science has changed, its more...}

- collaborative, with bigger teams

- international

- expensive

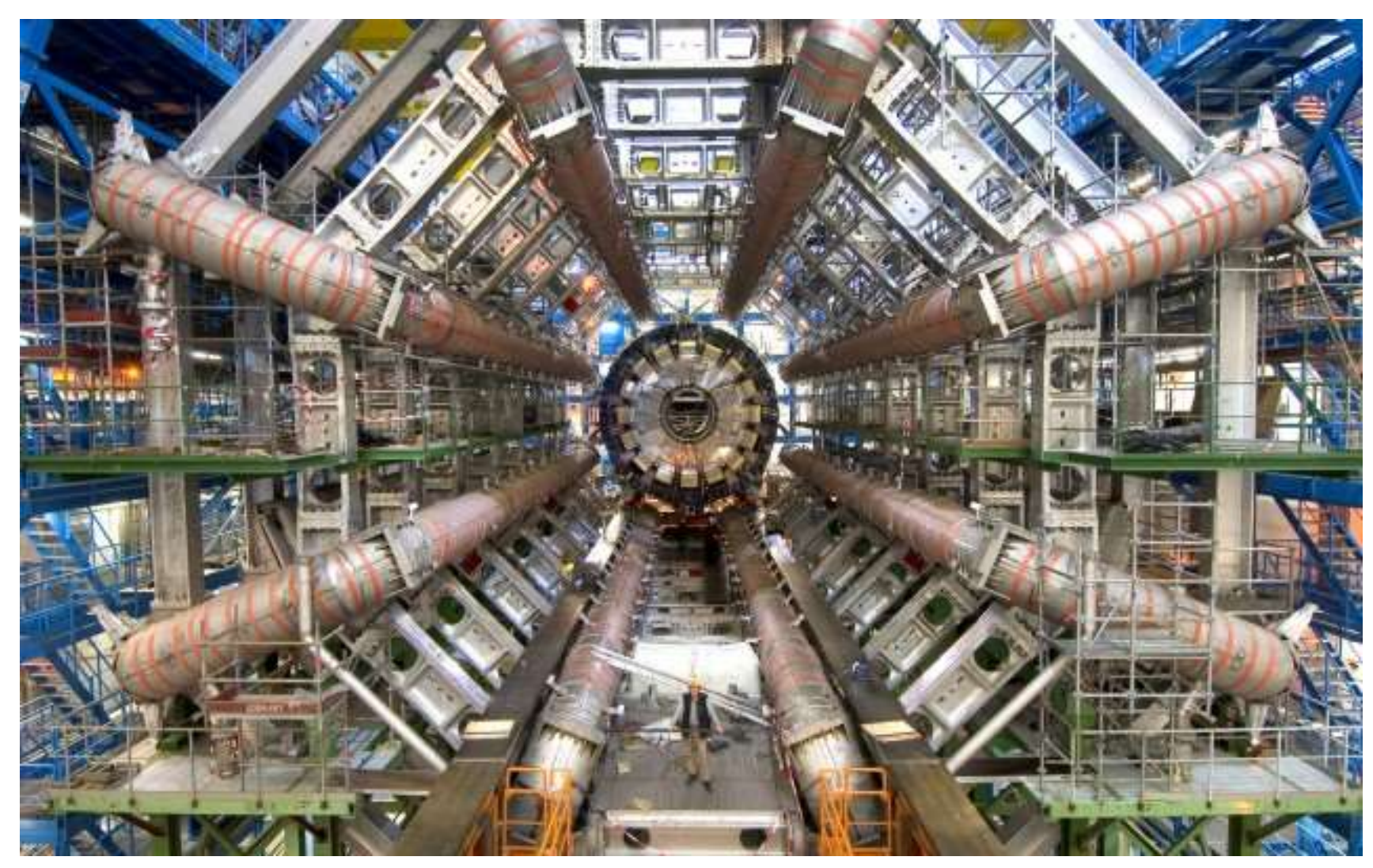


What does leadership mean in global, collaborative science? 
The many faces of mobility leadership 
Who/what do we think of as "leader"?

- People?

- Institutions?

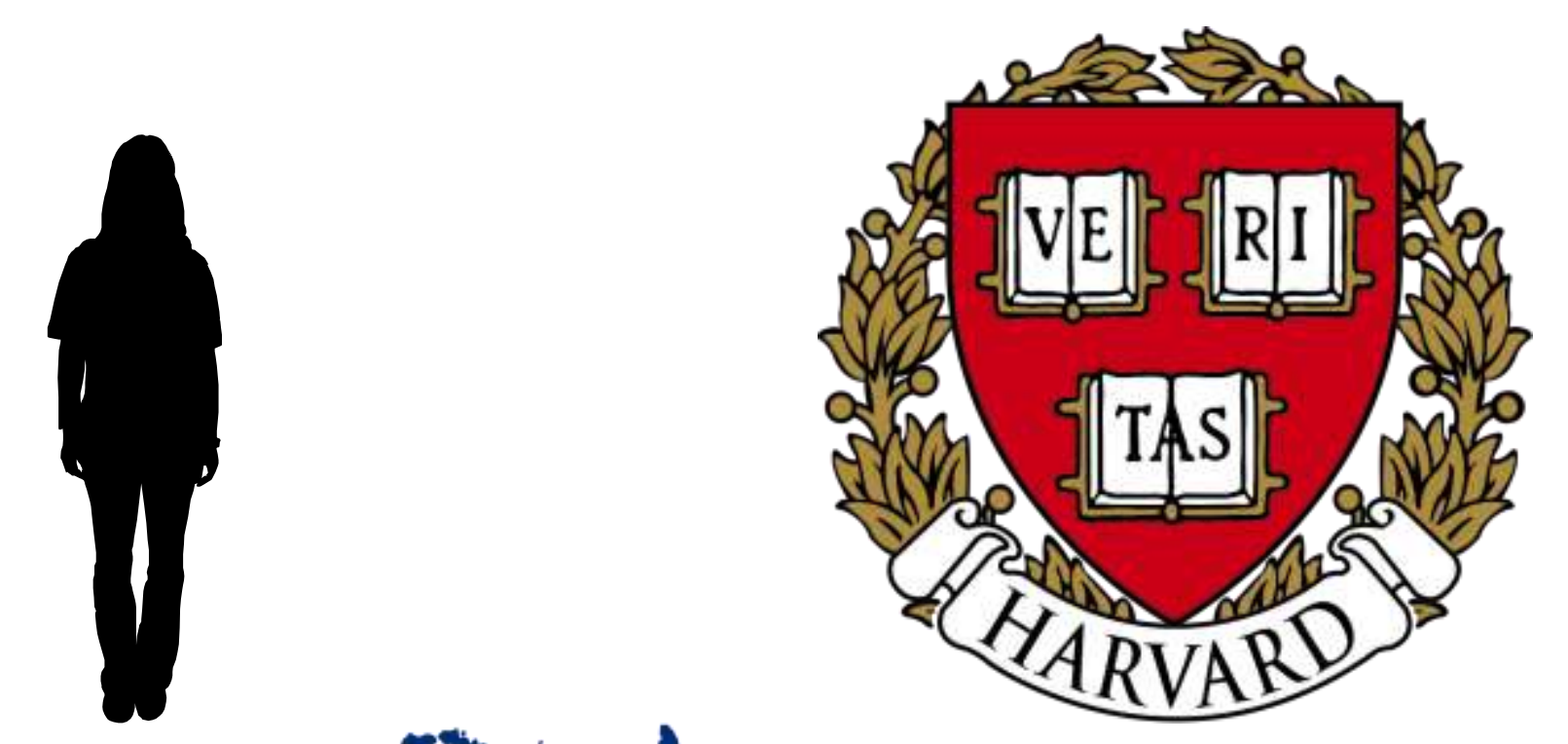

- Countries?

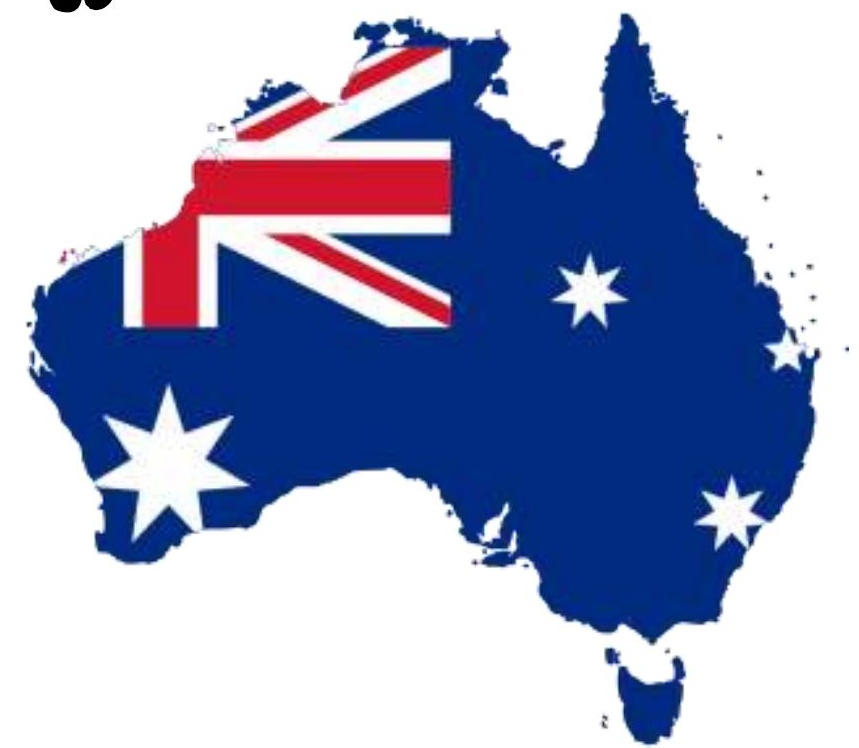


What makes them a leader? 


\section{Leadership in an activity measure}

- Who produces the most publications?

-Who receives the most citations?

- Who builds most on the most recently published literature?

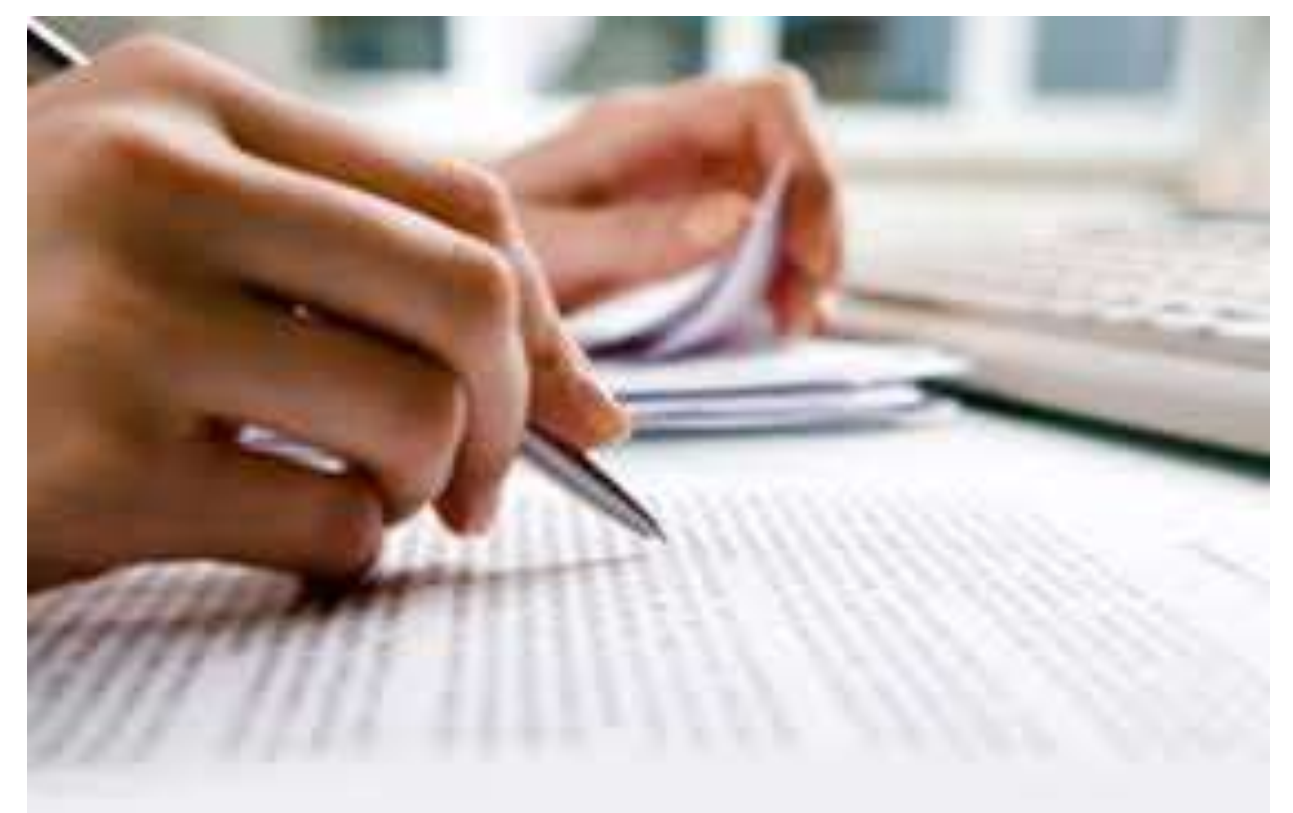




\section{Leadership in expenditure}

-Who spends the most money? 


\section{Leadership in contribution}

- Who contributes the most to international publications?

- Authorship indicates leadership

- First

- Last

- Corresponding

- (ICMJE 2012 ; Moya-Anegón et al. 2013; Larivière et al.2016; Costas \& Iribarren, 2007; Van Leeuwen 2009; Chinchilla et al, 2016).

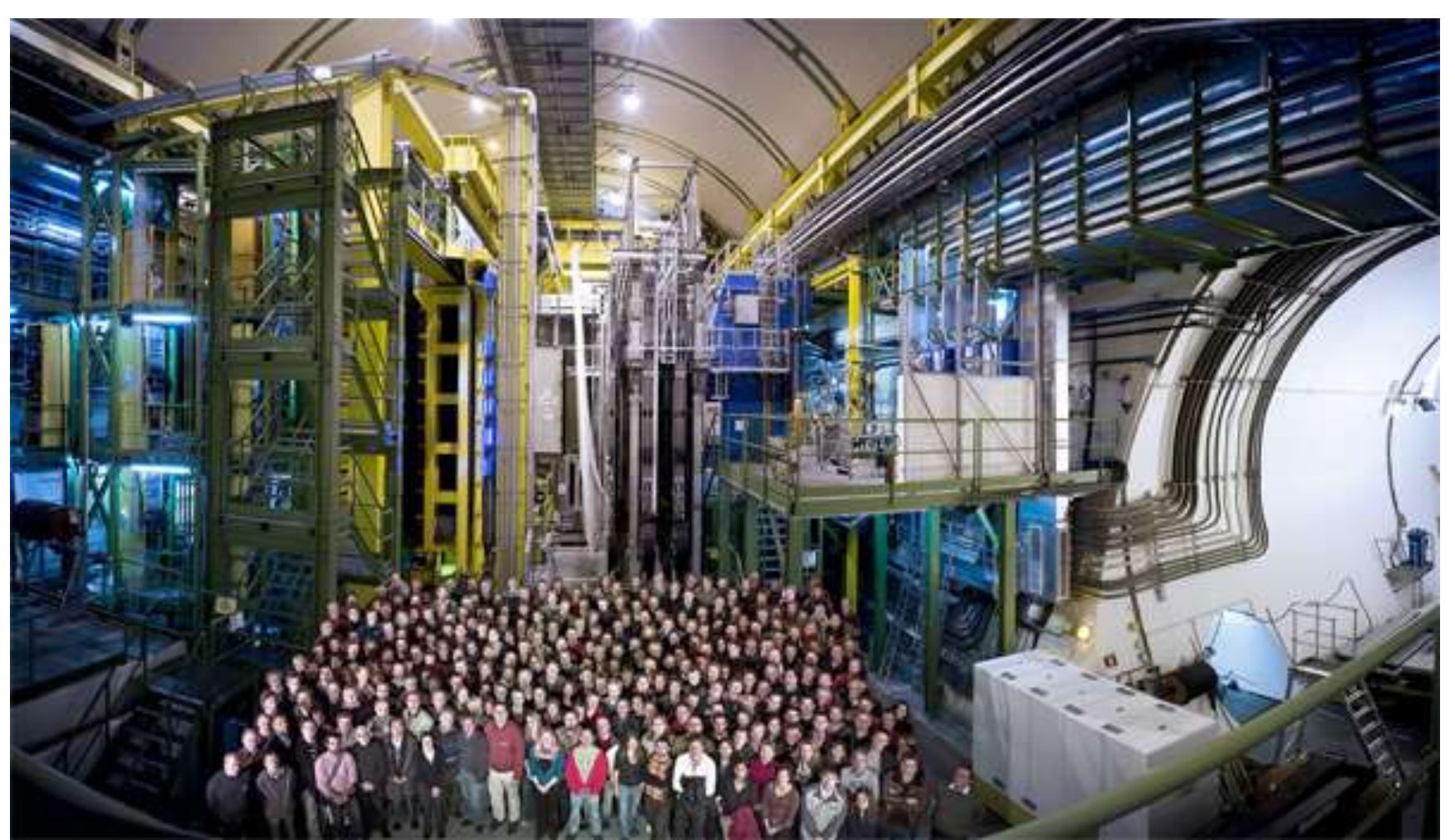


Many ways of thinking about leadership 
But here, we are concerned mostly with contribution at the country-level 
Country's leadership, mobility, and collaboration has been studied, but... 


\section{Well-studied "elite" countries}

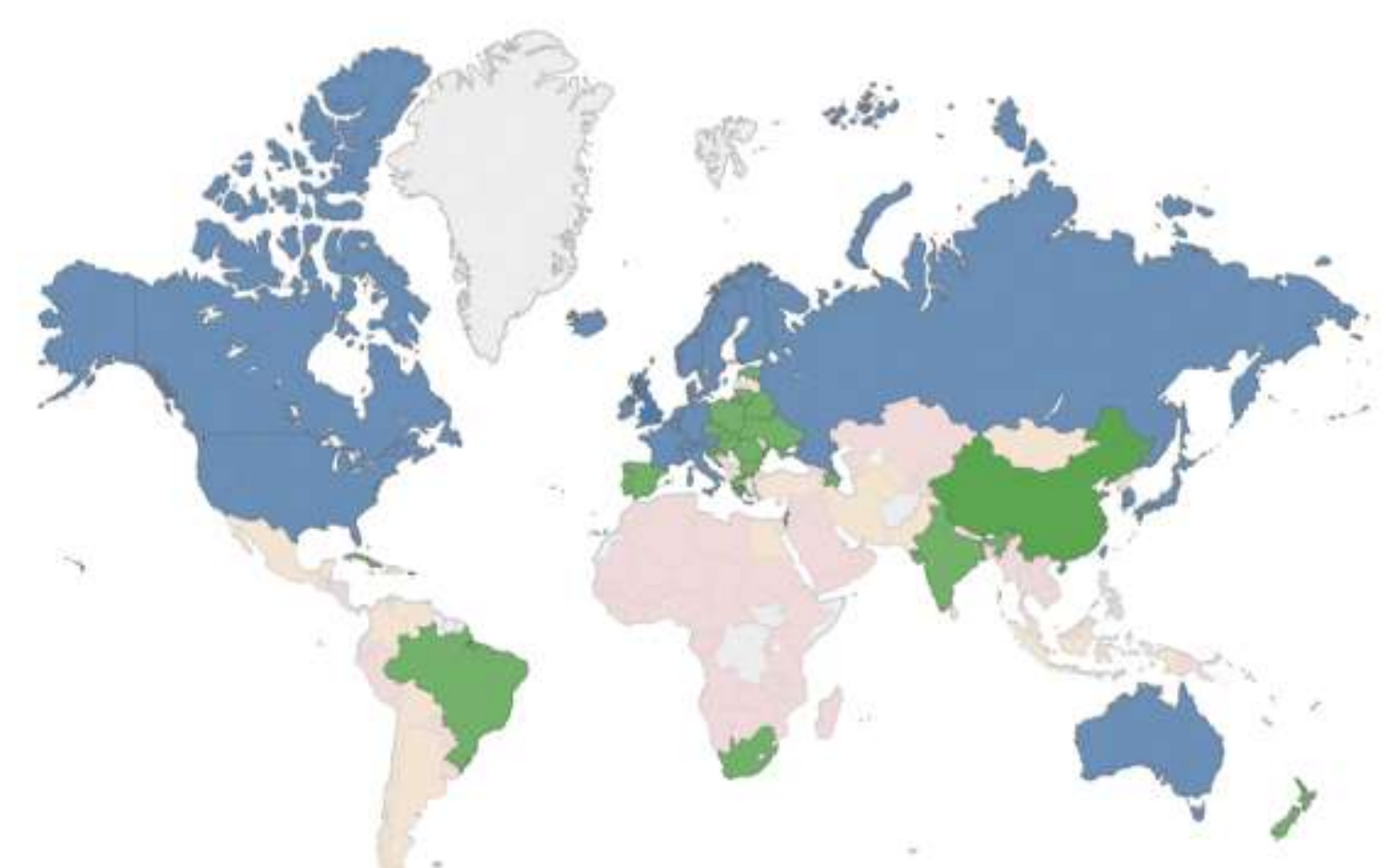


Understudied Periphery 


\section{Moving away from the elite}

To understand the global system of science, we need to move away from the "elite" and towards a comprehensive analysis of international scientific partnership

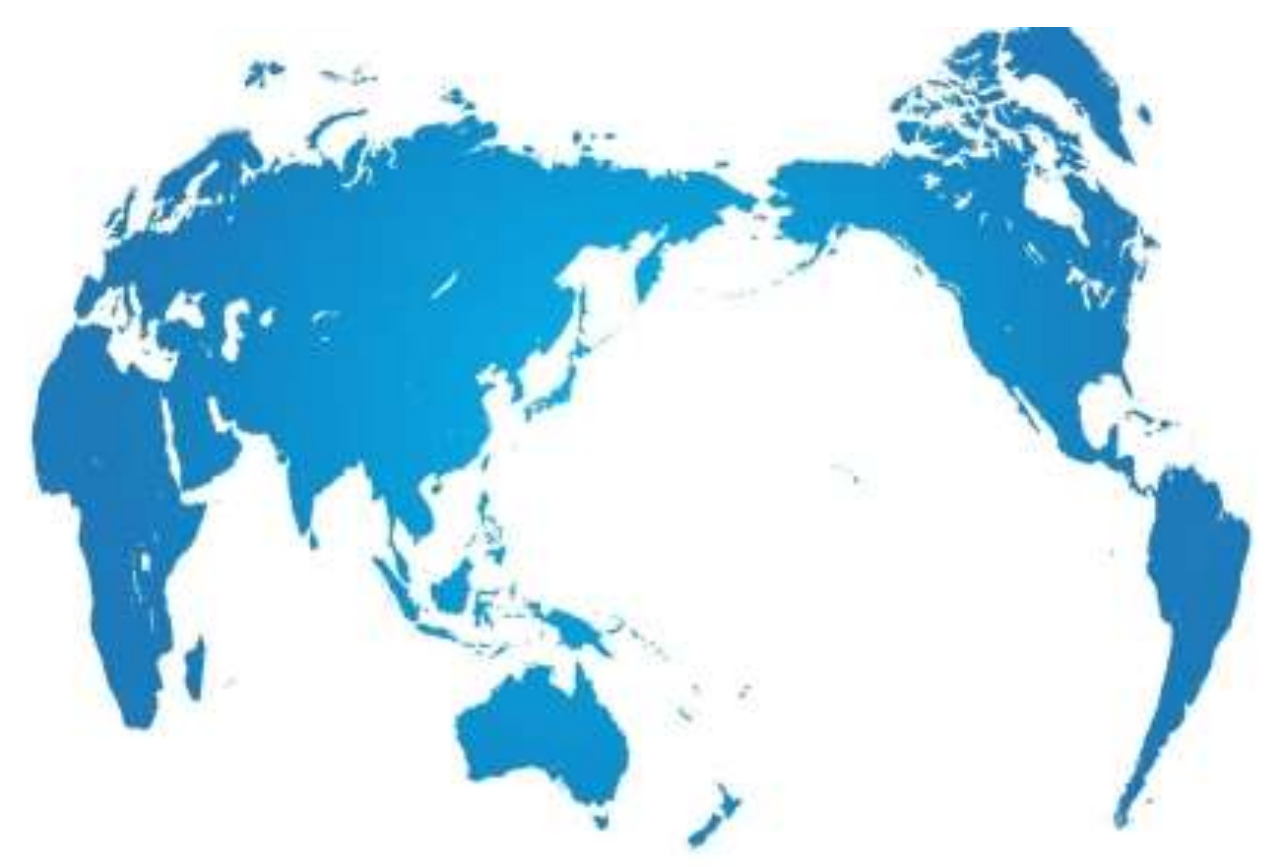


Goal: Investigate the costs/benefits of international collaboration and leadership in science for countries

While bringing non-elite countries into the fold and assessing the impact of 


\section{Terminology and considerations}


3 categories of collaboration Defined at the publication level 
No collaboration
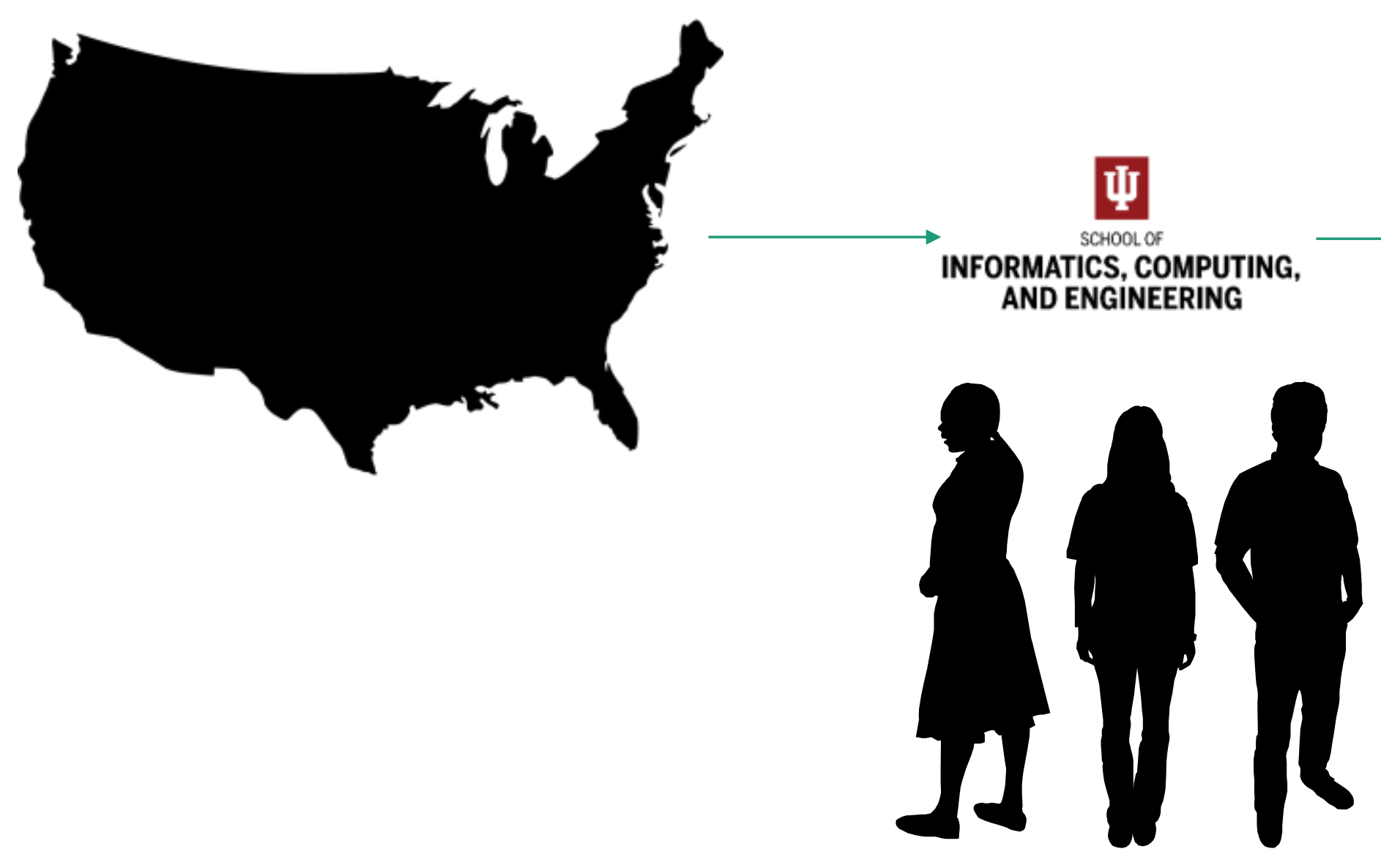


\section{Domestic collaborations}

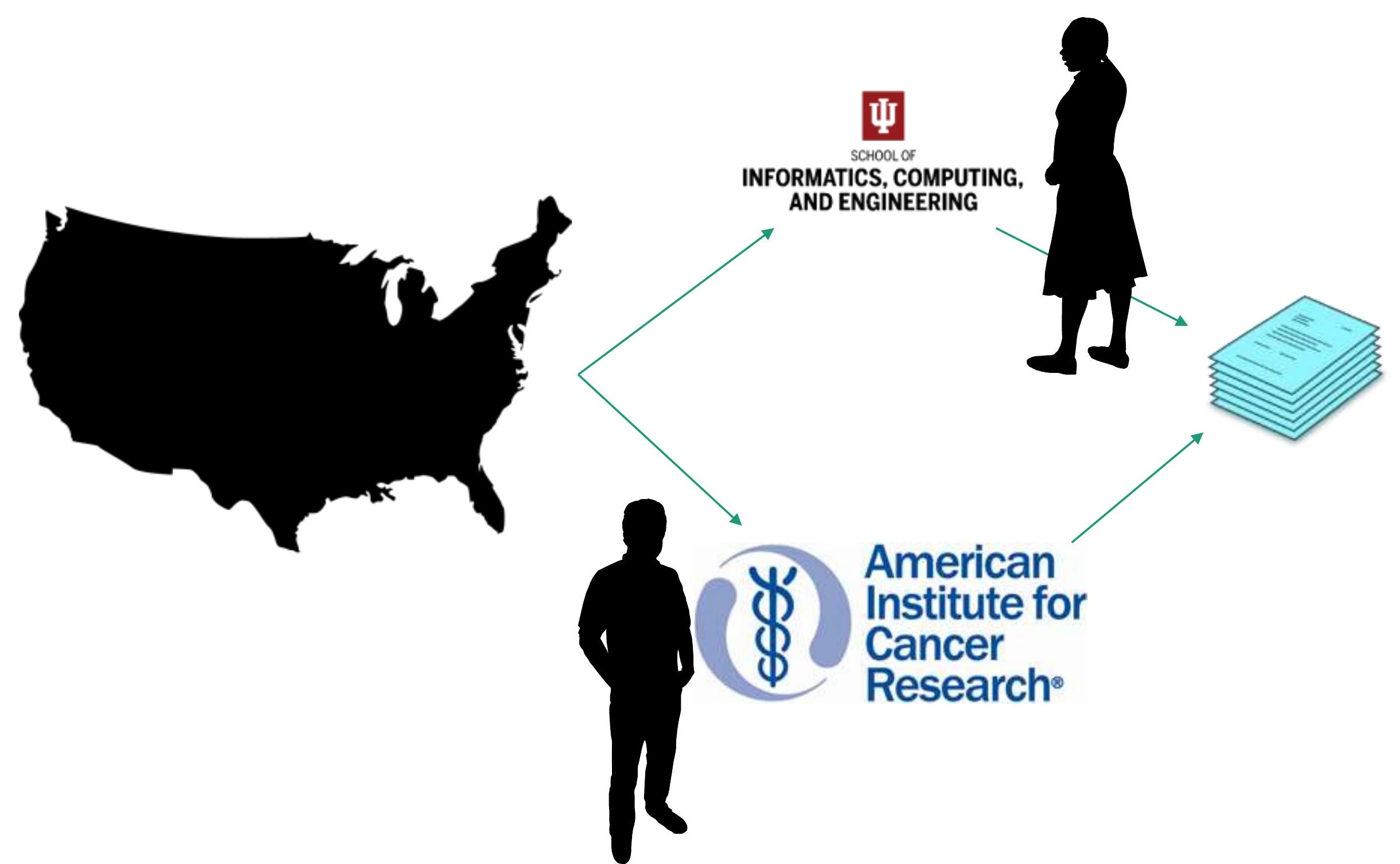




\section{International collaboration}

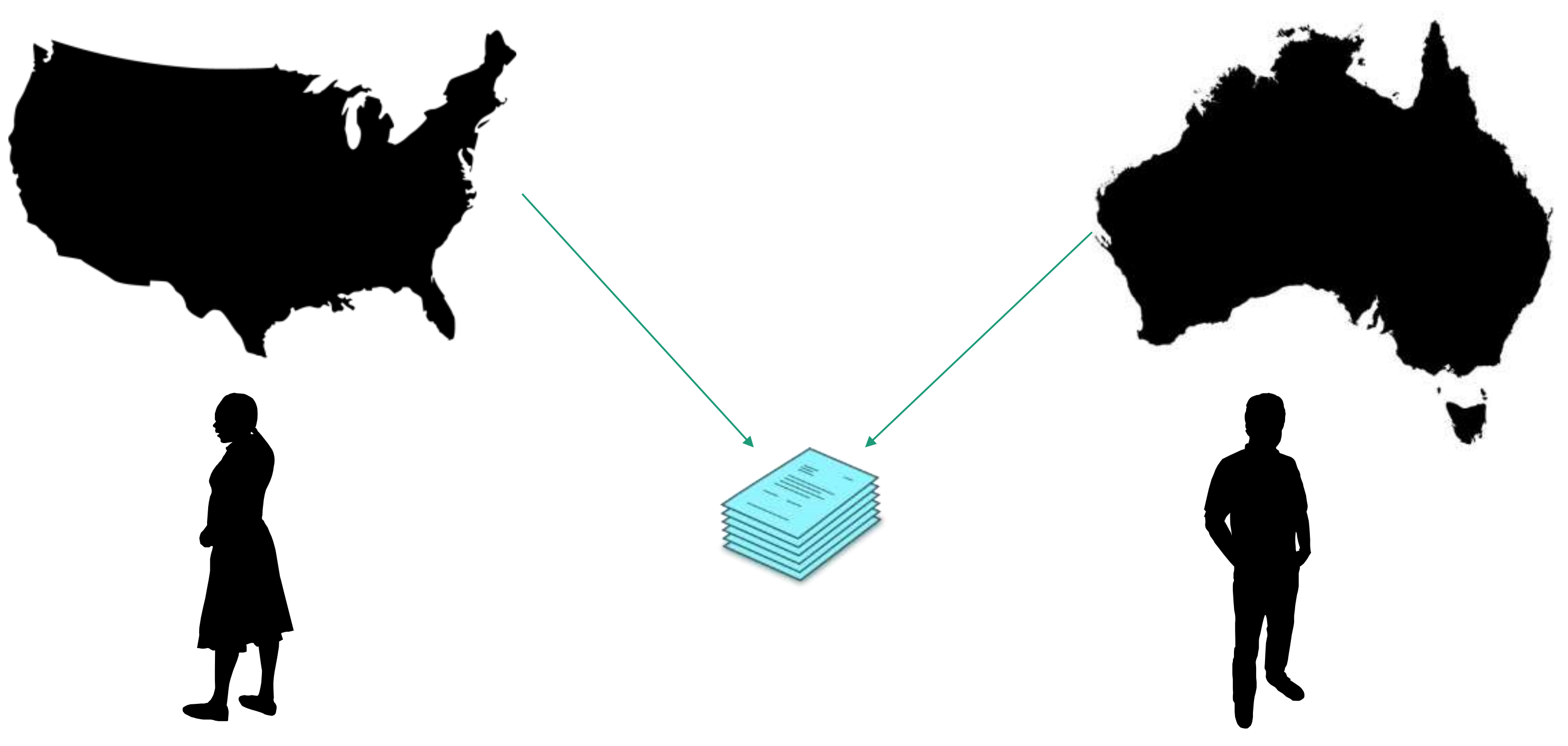


Operationalizing leadership:

Corresponding, first, or last authorship... 


\section{Leadership relative to size}




\title{
Leadership relative to size...
}

\author{
8 total \\ 2 leading
}

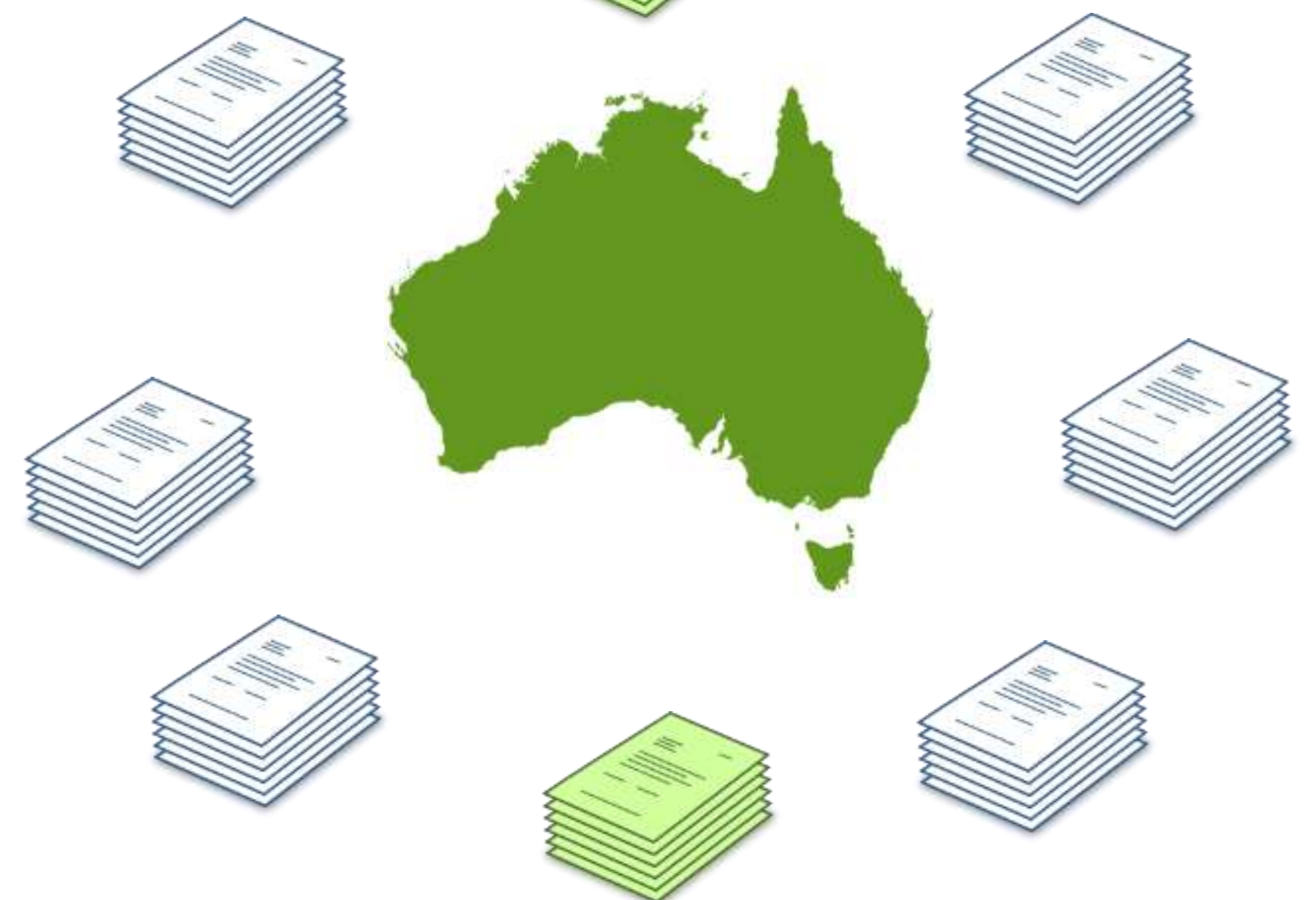




\section{Leadership relative to size...}

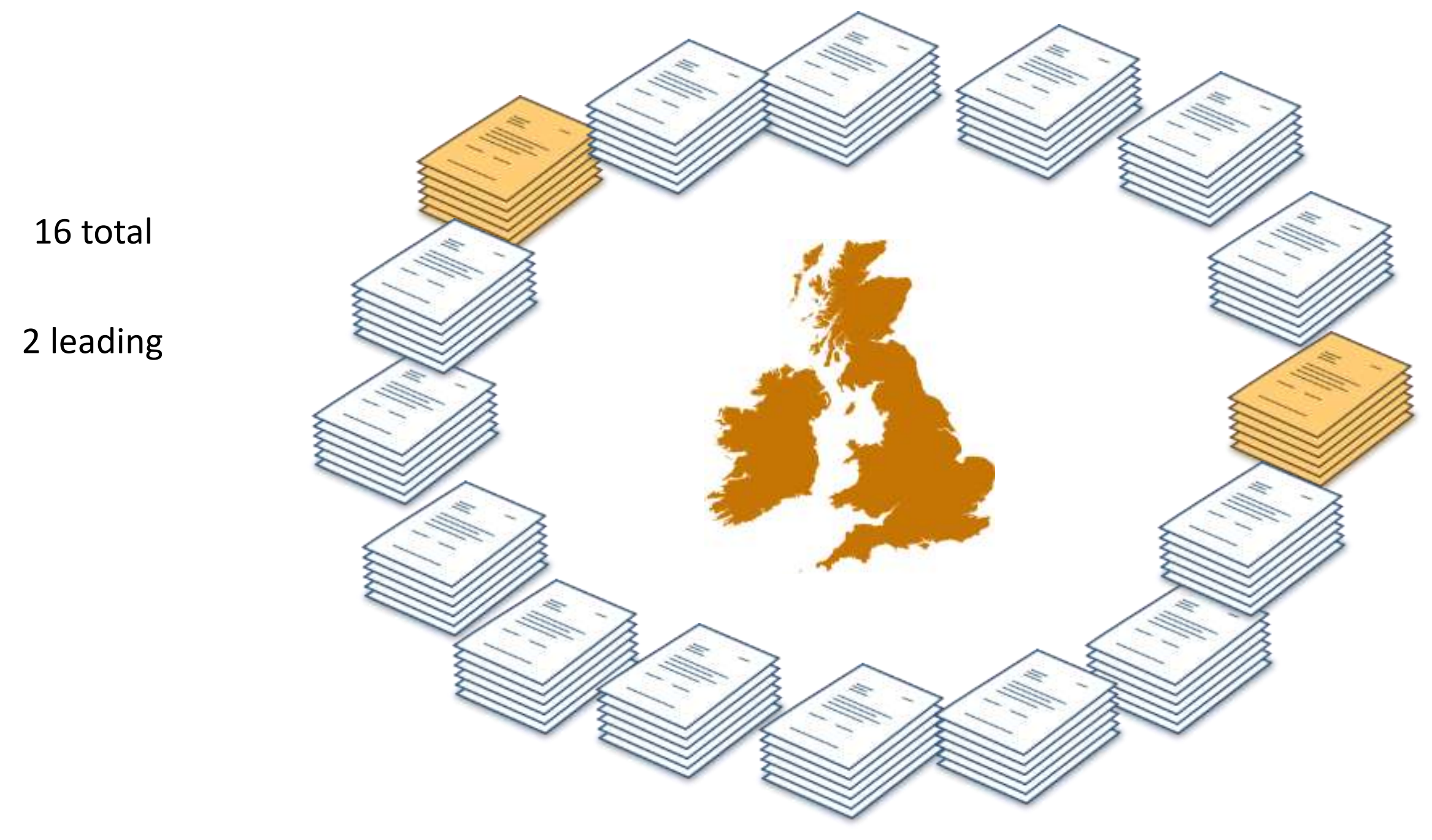




\section{Data and methods}




\section{Web of Science}

\section{Period: $2000-2016$}

papers, reviews and conference proceedings

\section{$19,460,980$}

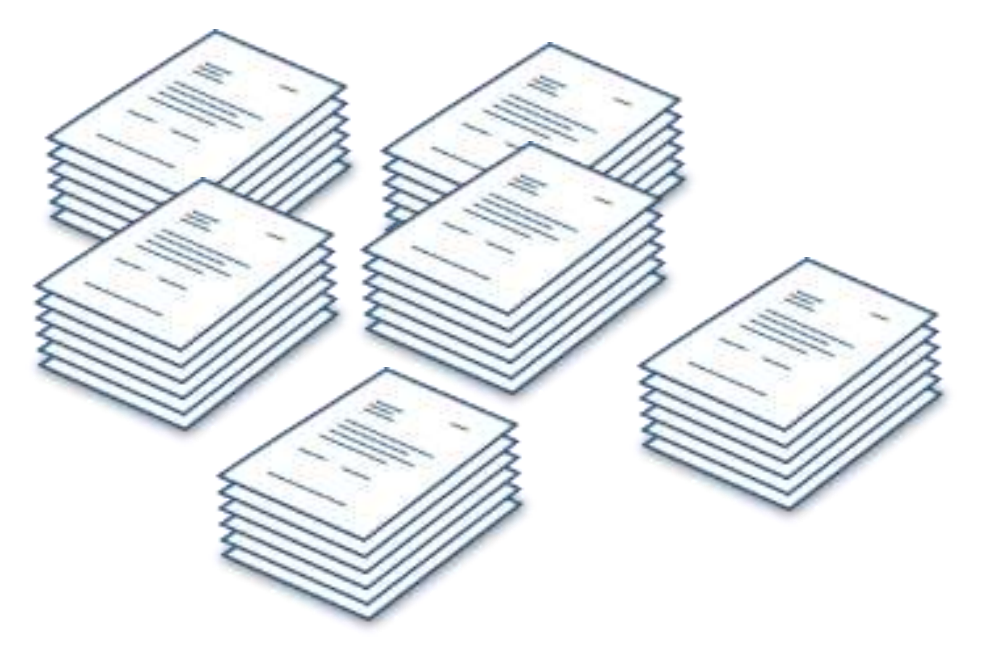

100 Countries

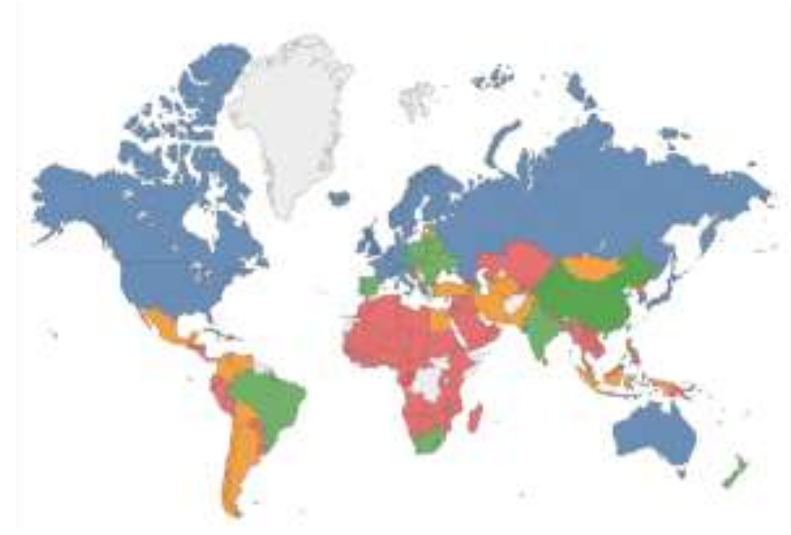


Research and development expenditure (\% of GDP)

Expenditures for research and development are current and capital expenditures (both public and private) on creative work undertaken R\&D covers basic research, applied research, and experimental development.

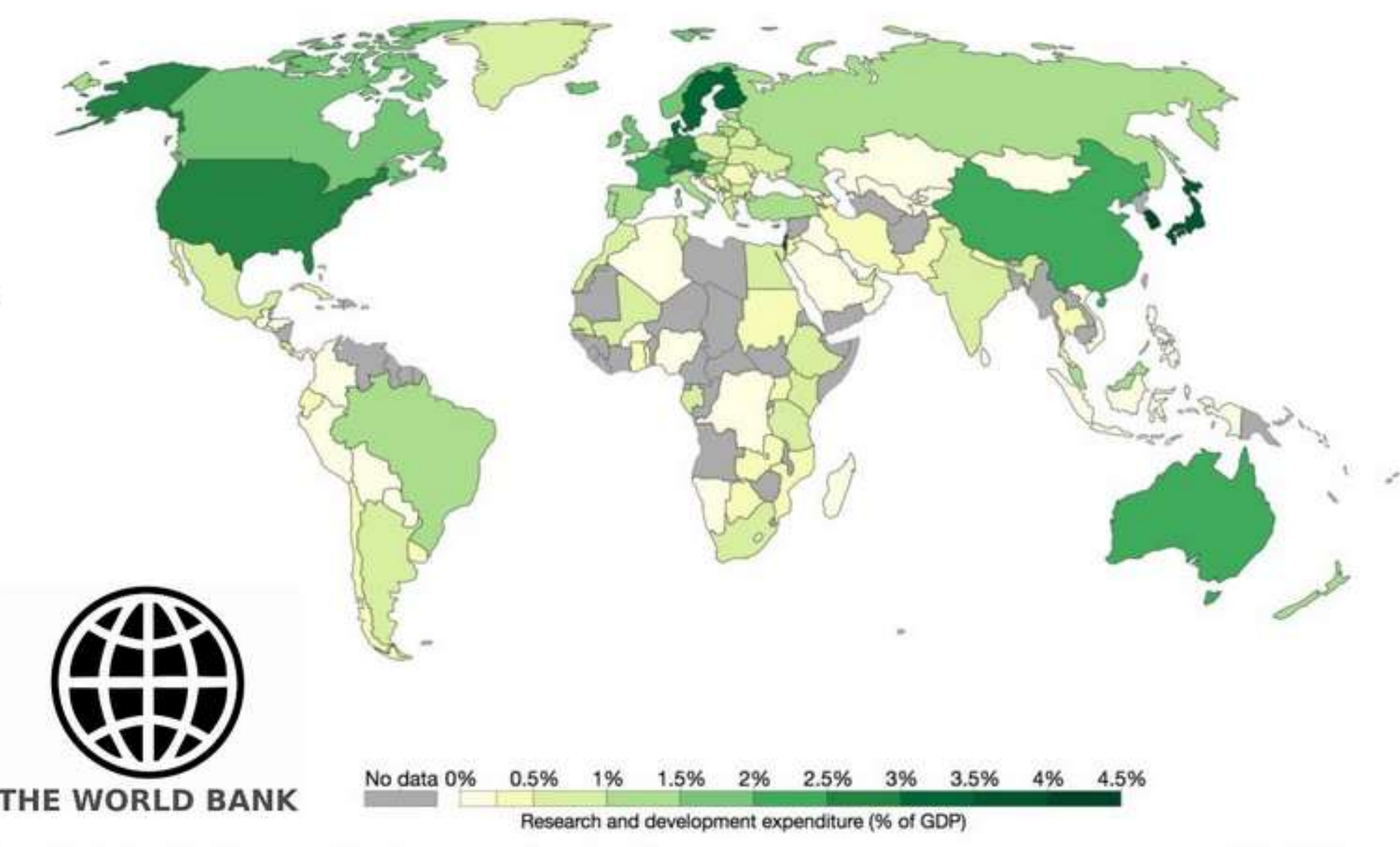

Source: World Bank - WDl: Plesearch and development expenditure (\% of GDP) 
Results 


\title{
Collaboration profiles
}

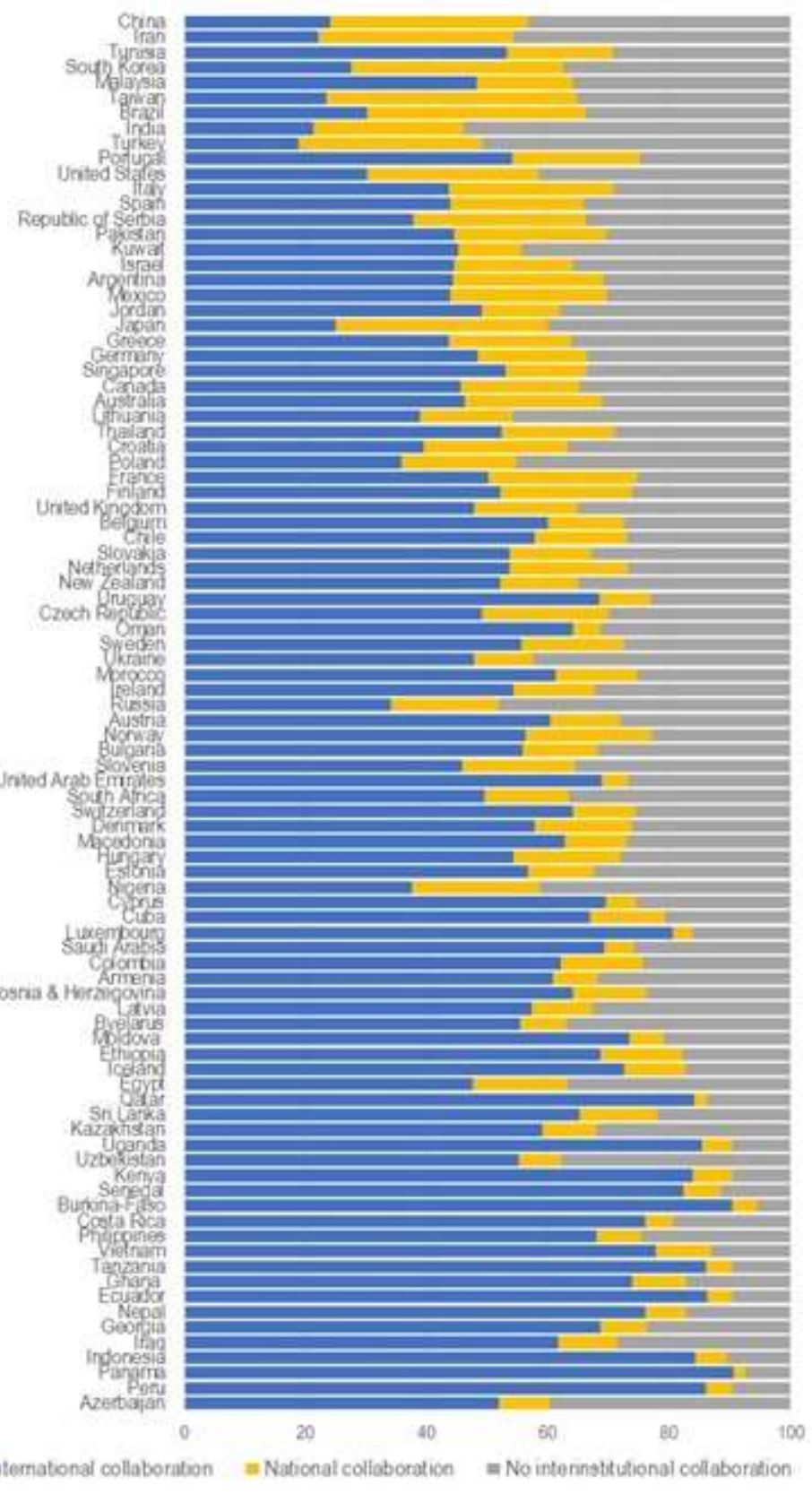

\author{
Blue $=\%$ International collaboration \\ Yellow $=\%$ National collaboration
}

Grey $=\%$ No collaboration 


\section{Collaboration profiles}

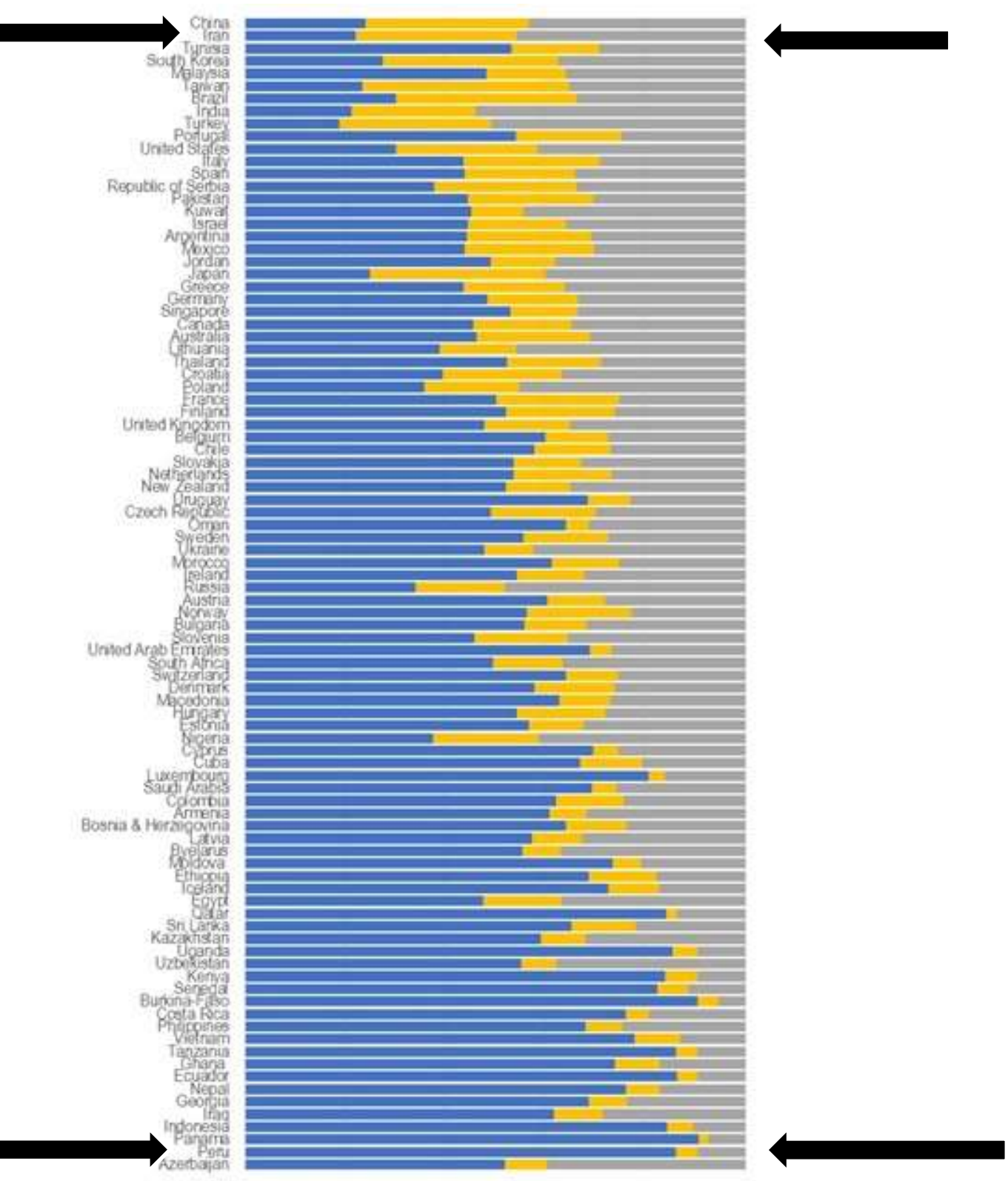

China:

Low international

collaboration

High domestic

collaboration

\section{Peru:}

High international collaboration 


\section{Collaboration profiles -> Leadership}
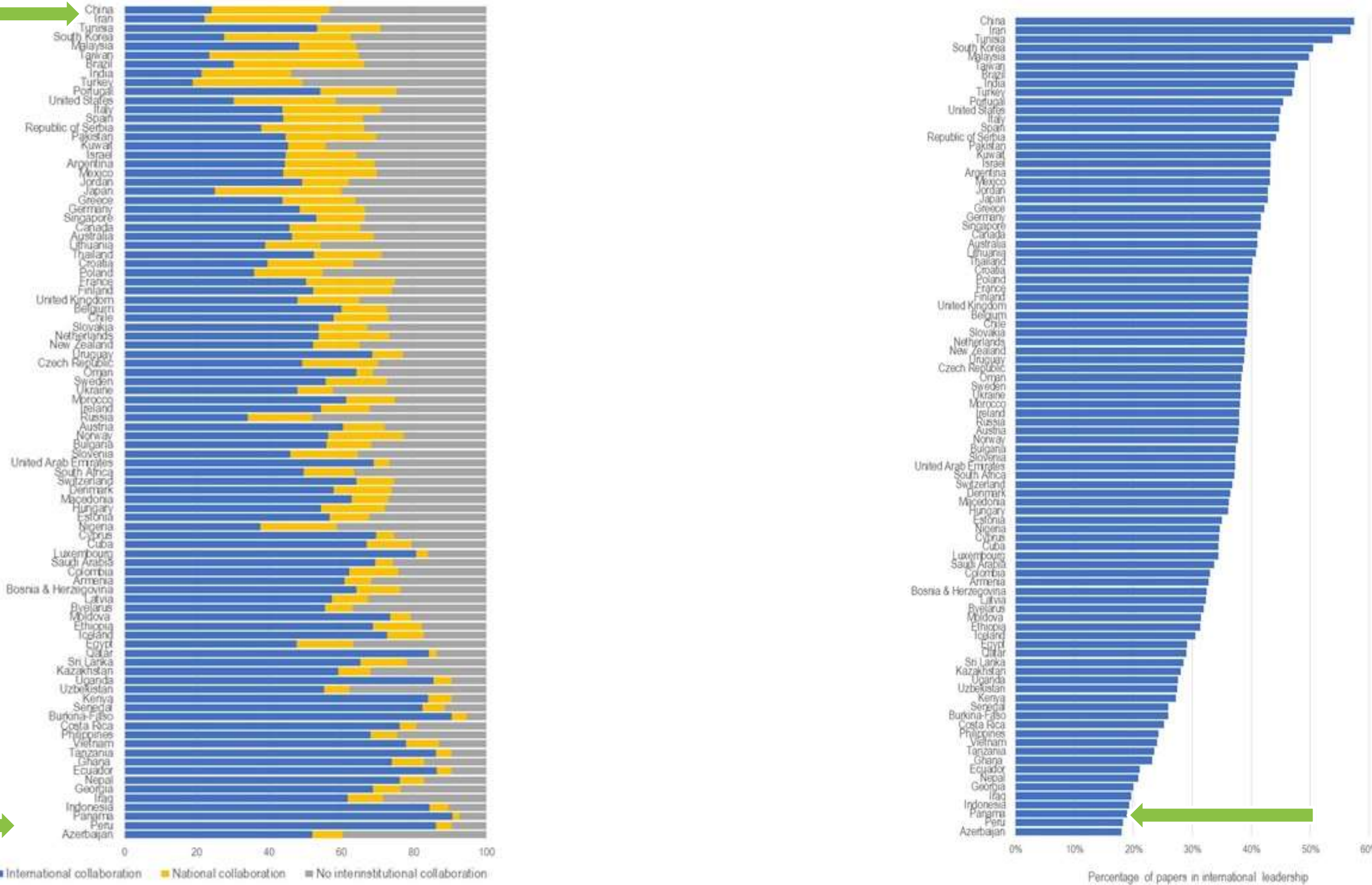
The more dependent on international collaboration, the less they are in leadership positions
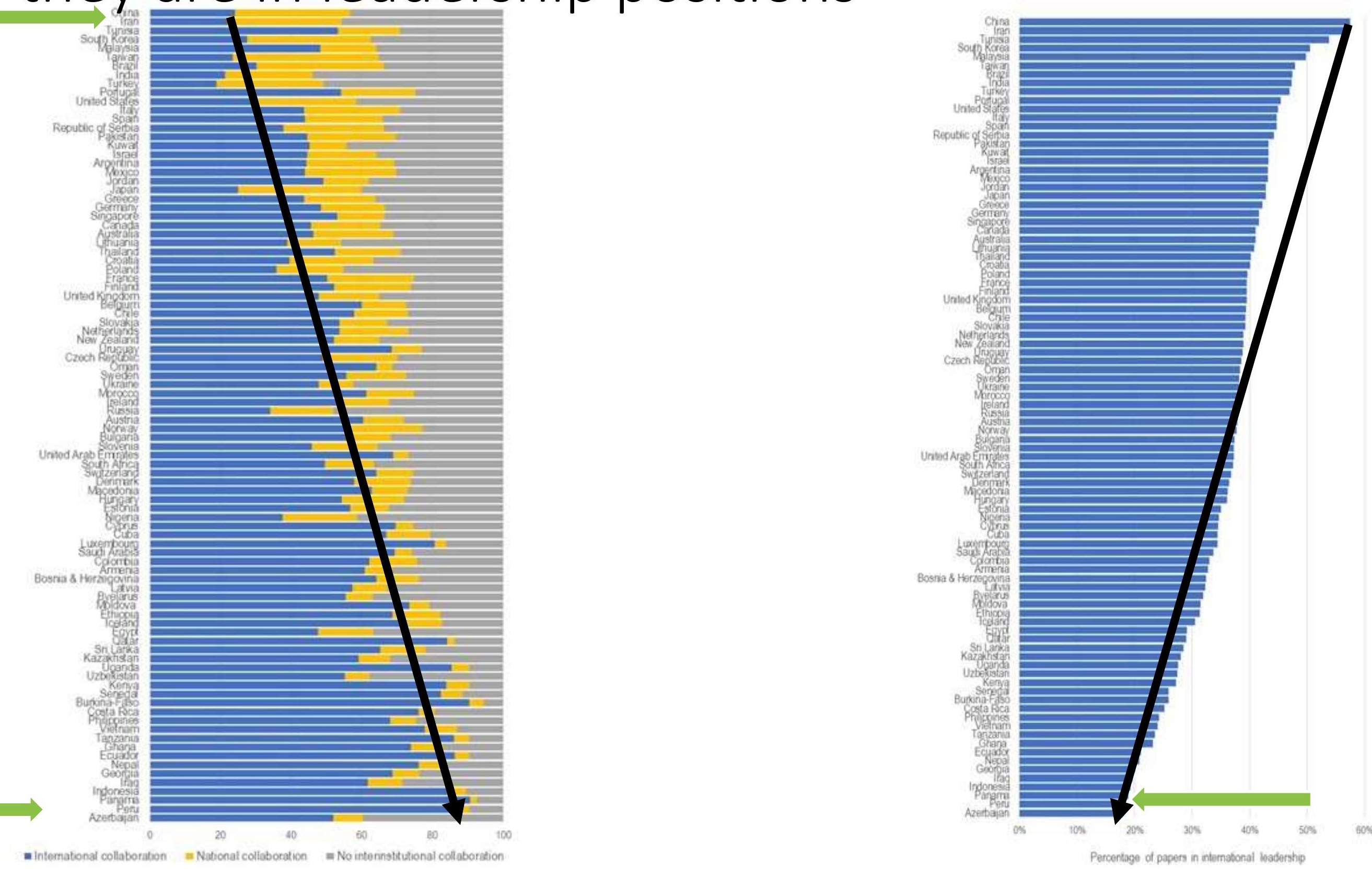


\section{Citation score (MNCS) by collaboration type}

$\mathrm{X}$-axis $=$ MNCS

Blue dot = international collaboration

Red $\mathrm{x}=$ National (domestic) collab

Green triangle $=$ No collaboration 


\section{International collaboration results in high-impact research}

Notice that the blue does (international collaboration) have a higher citation score than other dots

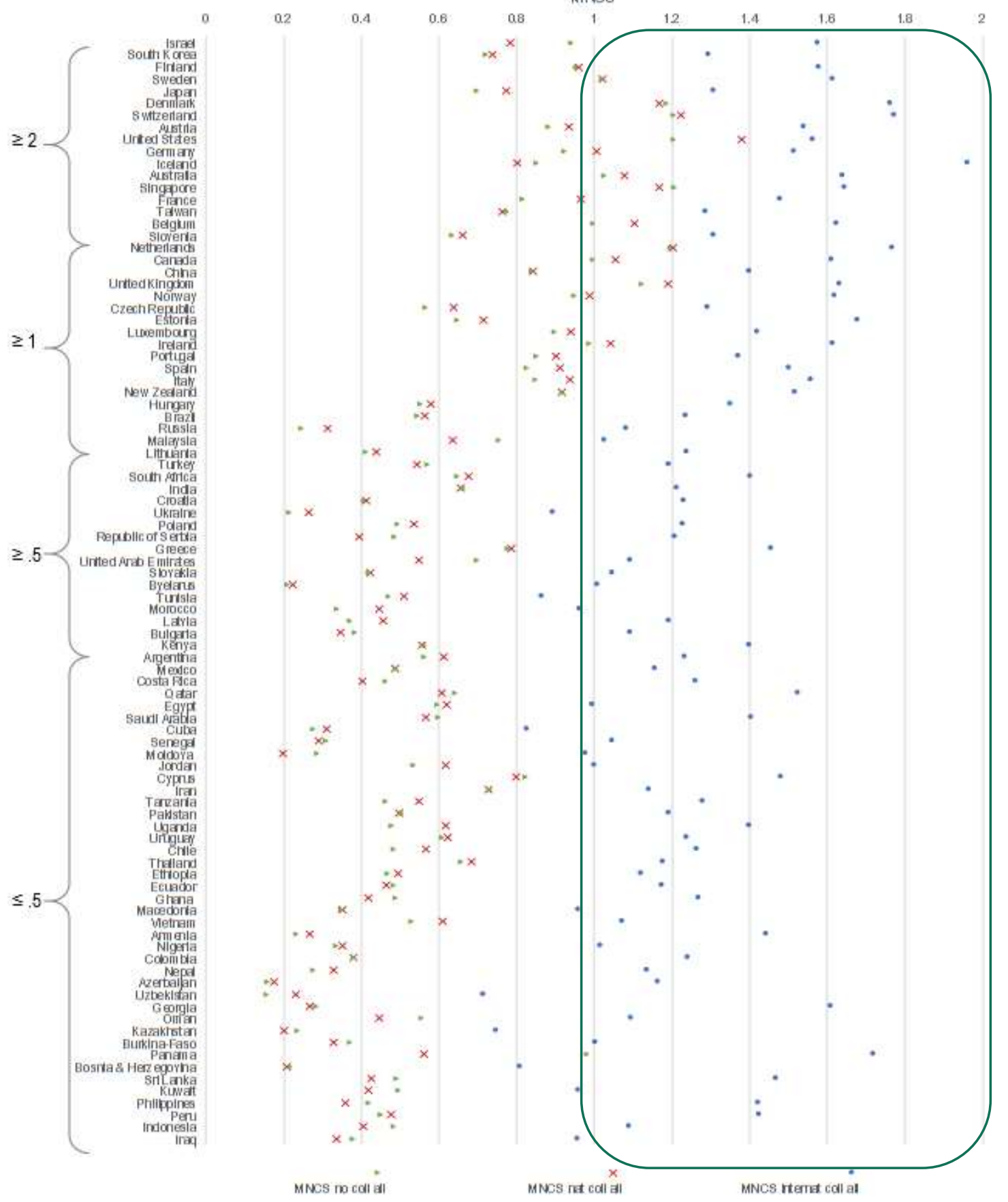




\section{$\%$ of international publications in leadership}

role and proportion of country's research expenditure

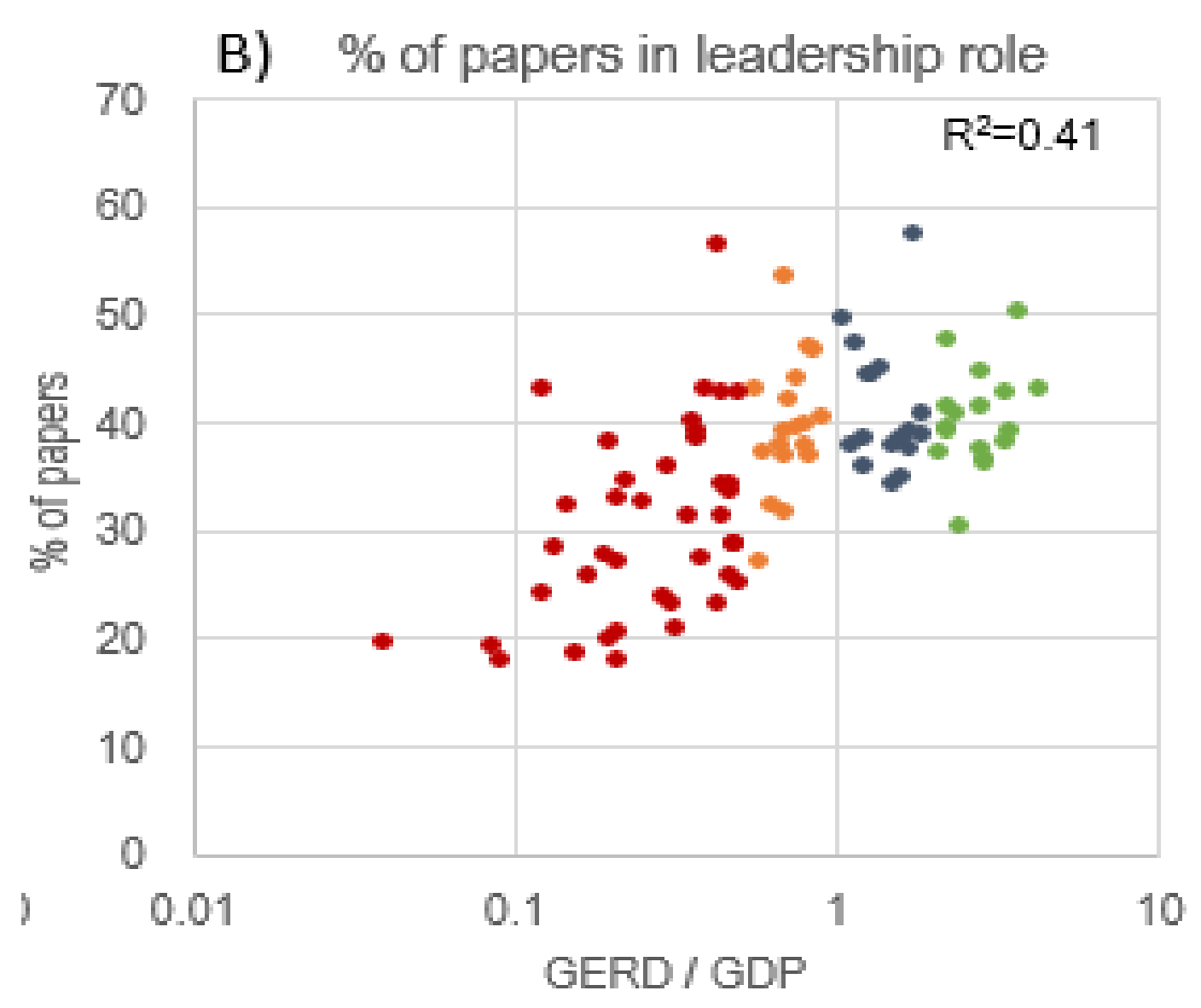


Scientifically "rich" countries are most often leaders

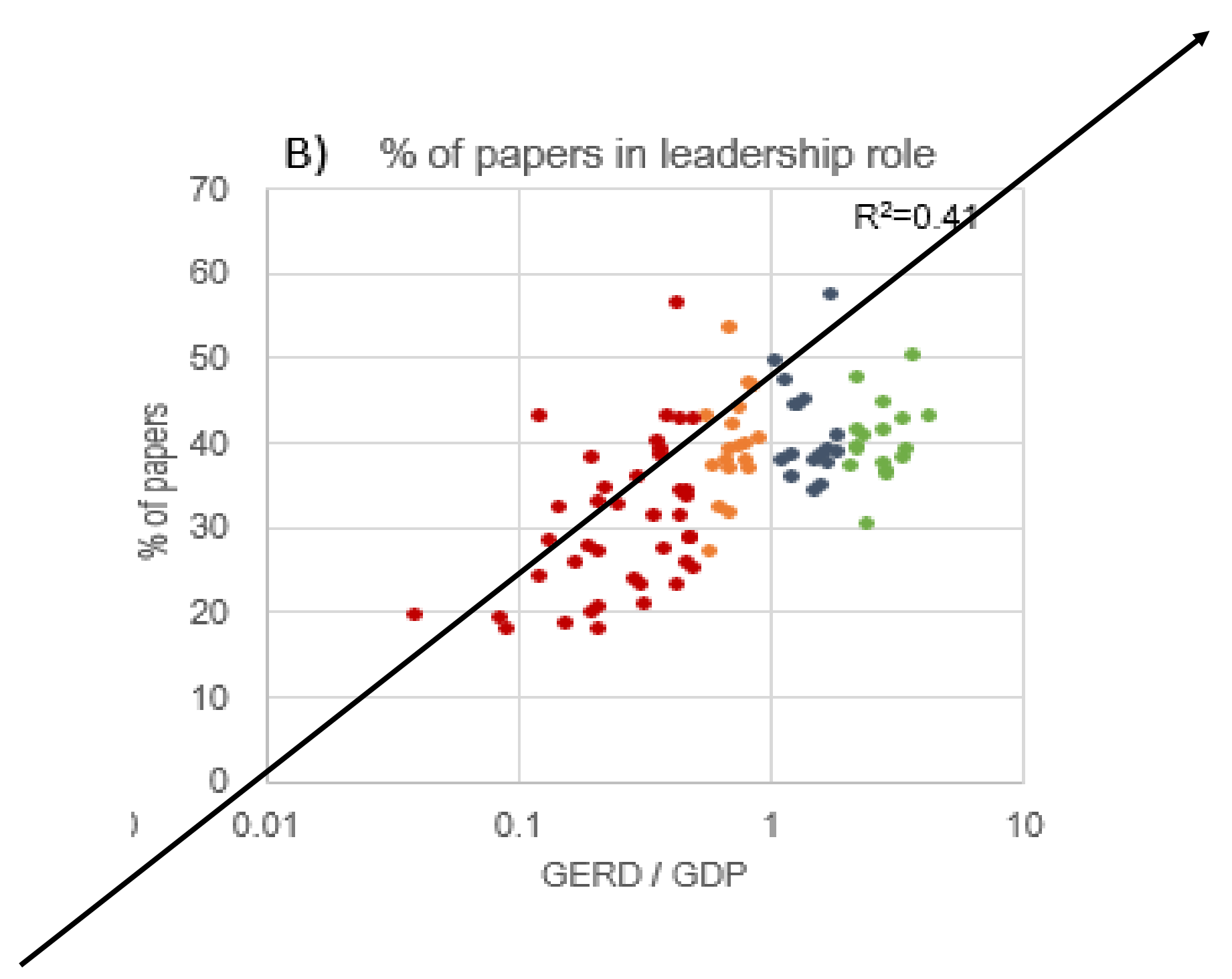


Now citation score (MNCS) by proportion research expenditure

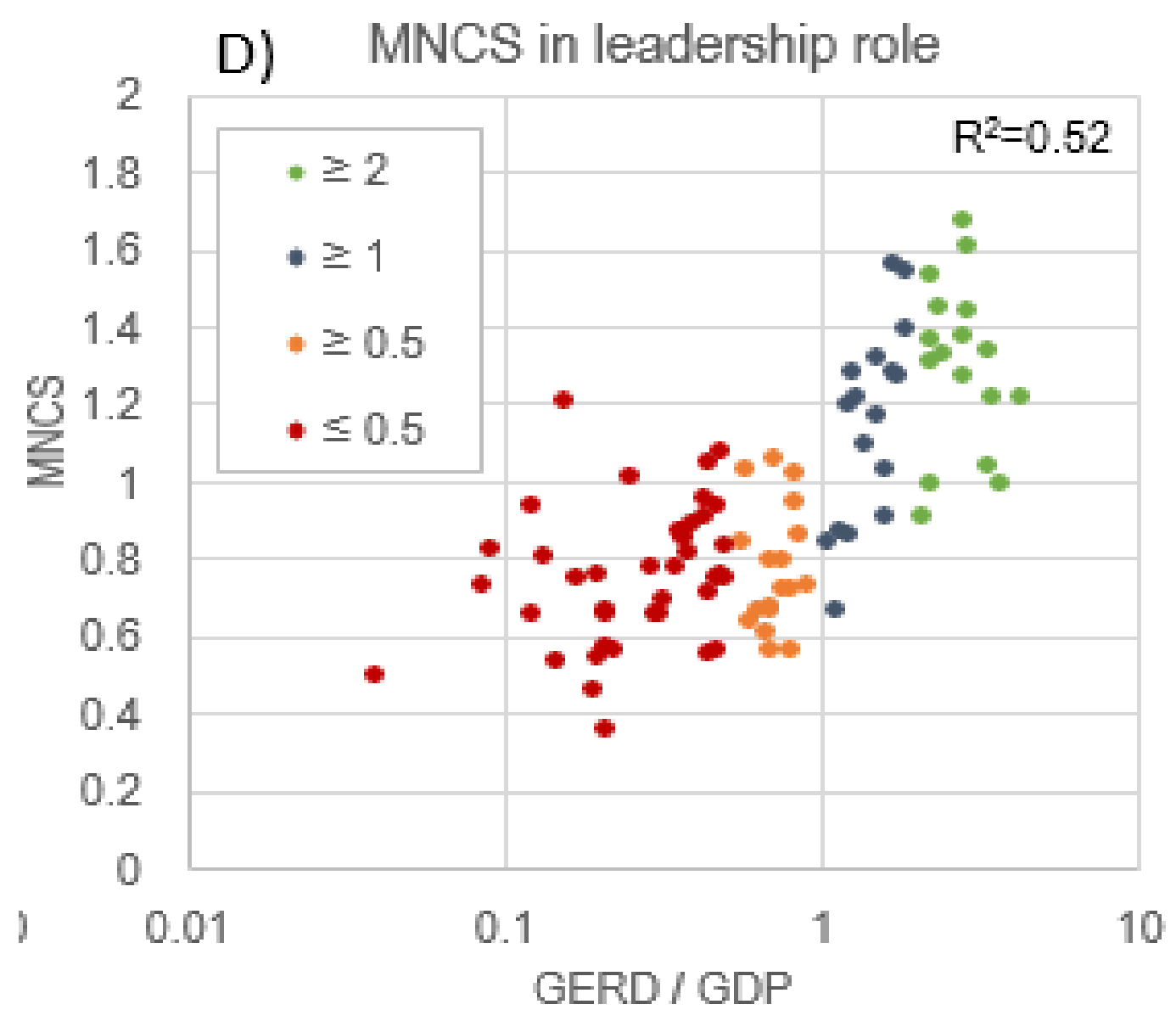


Scientifically "rich" countries also have higher citation scores when leading

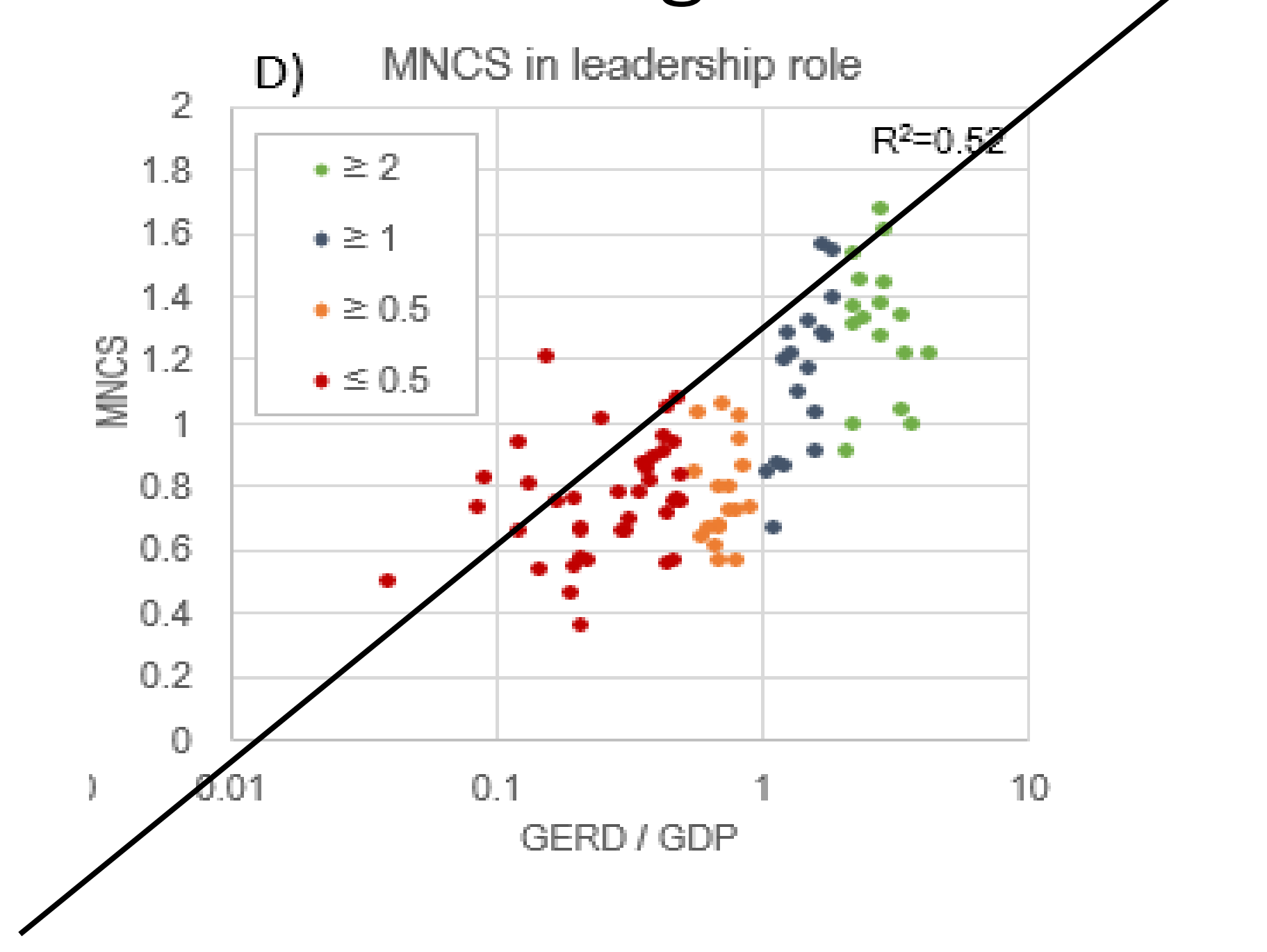




\section{Does leading give a citation benefit over not leading, in an international collaboration?}

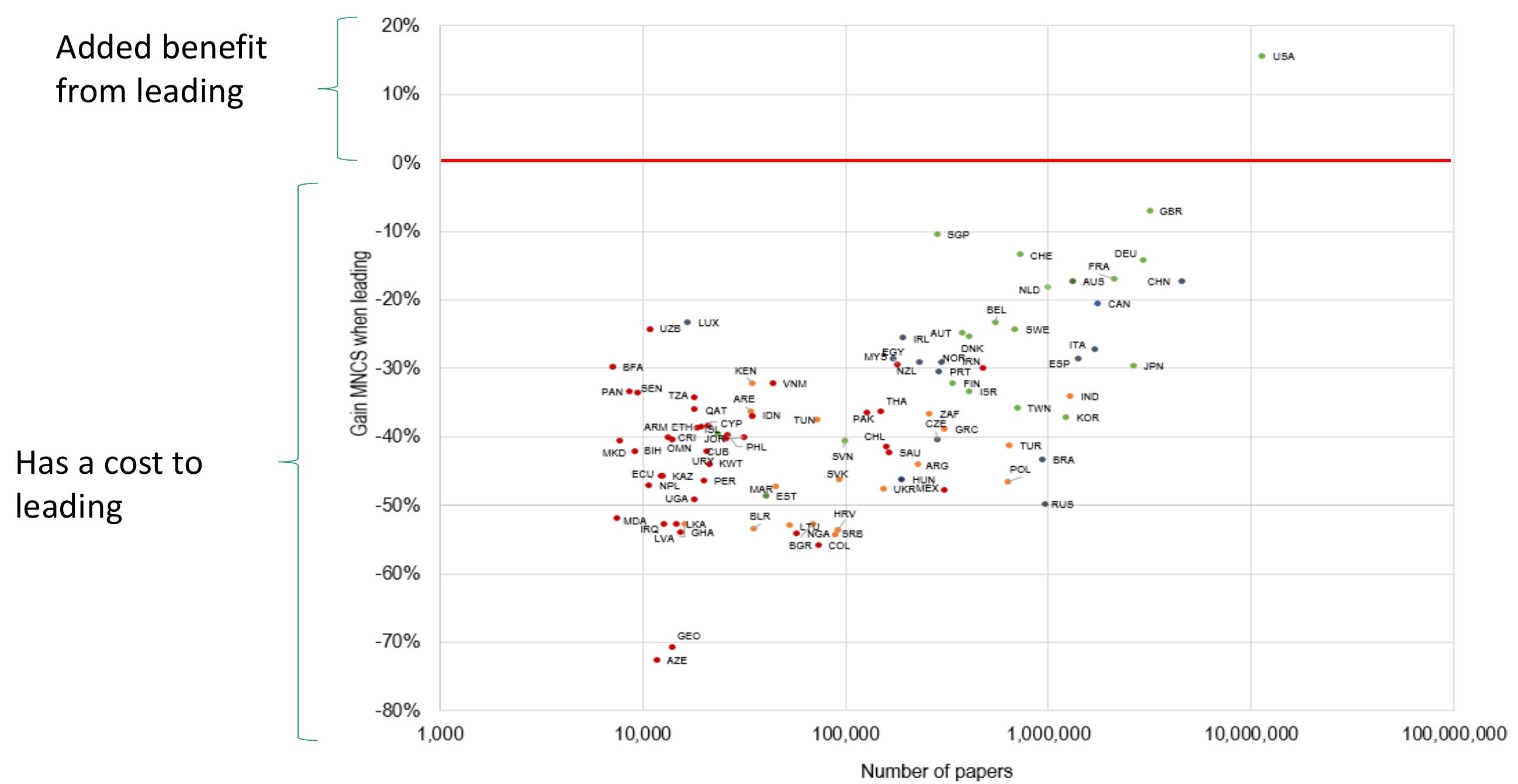




\section{Only the U.S.A. sees a citation advantage from leadership}

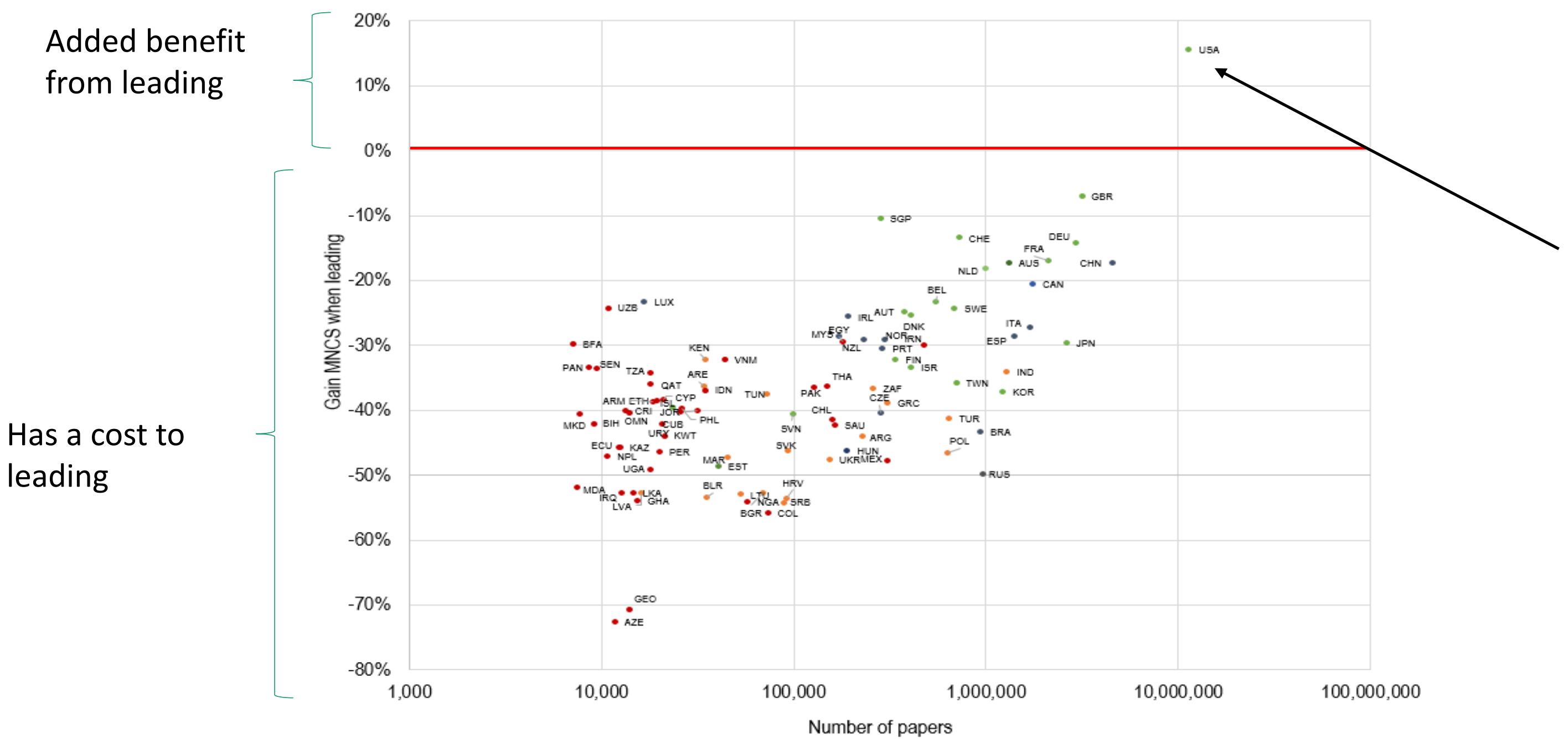




\section{International collaboration has benefit, but leadership rarely gives additional benefit}


But its complicated... 


\section{Heterogeneity...}

Non-leading country
Red $=$ high citation percentile Blue $=$ low citation percentile

Leading country

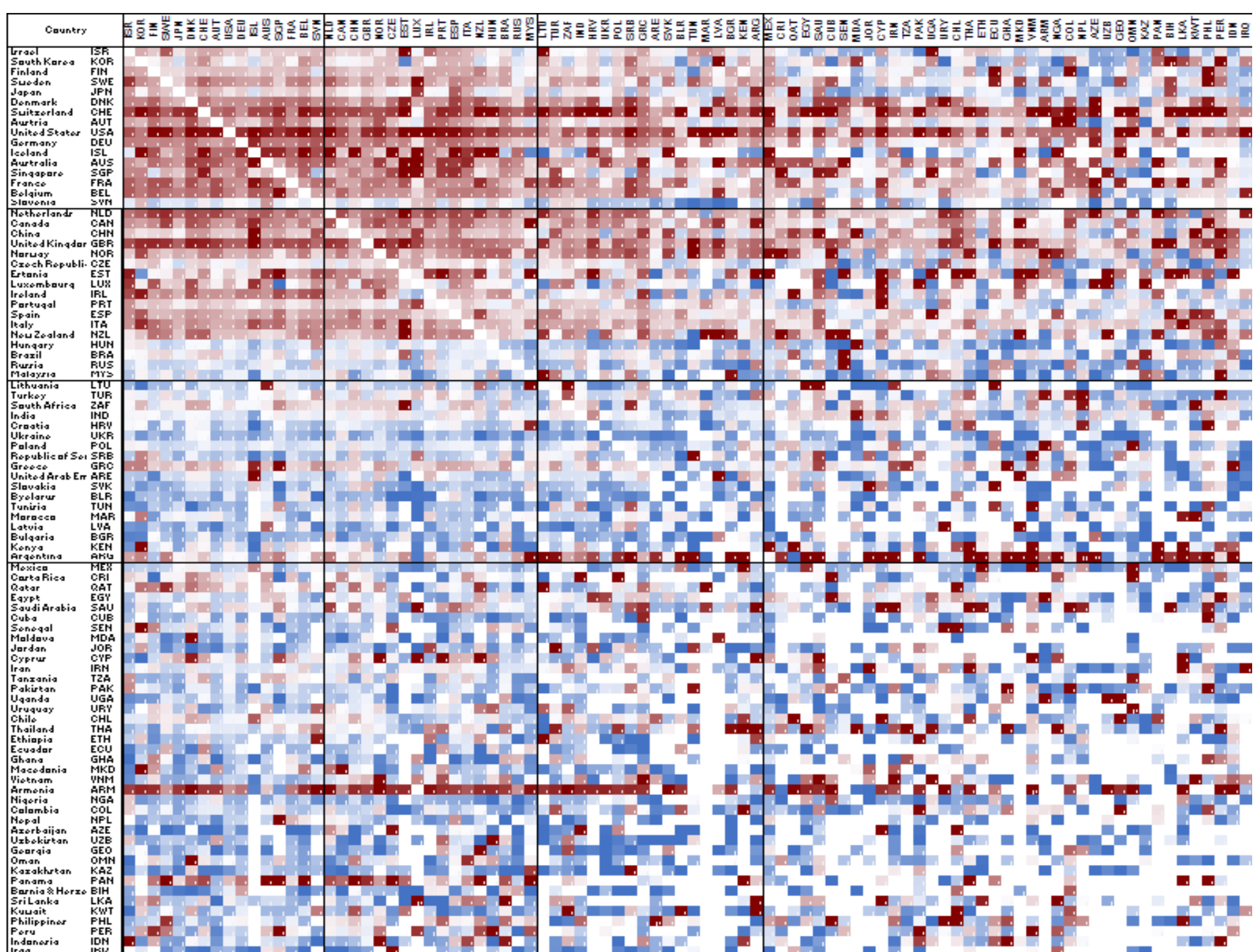


Non-leading country
Red $=$ high citation percentile Blue $=$ low citation percentile

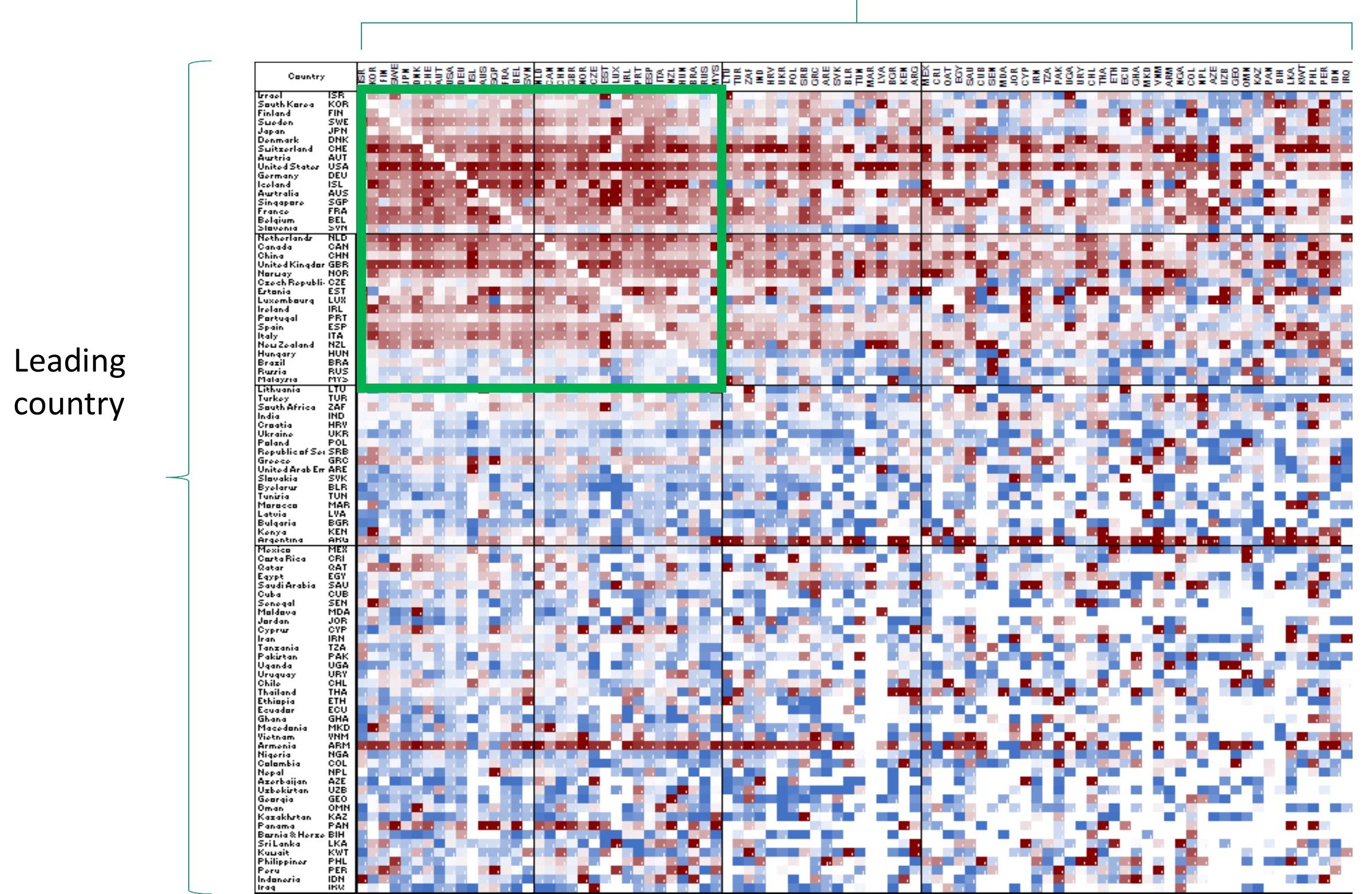

Strong collaborations 
Non-leading country
Red $=$ high citation percentile Blue $=$ low citation percentile

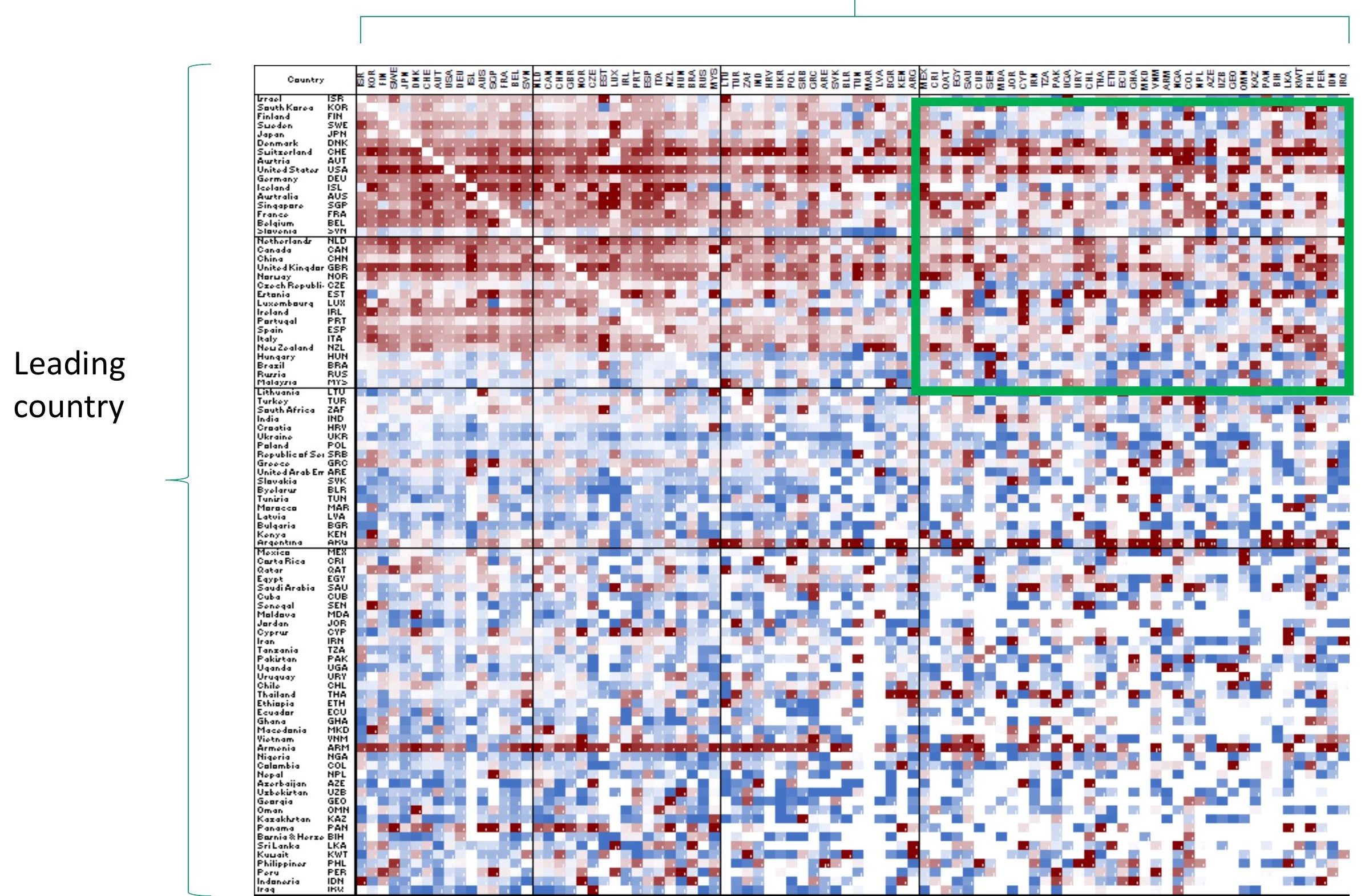

But not as strong collaboration between high and low investment countries 
Non-leading country
Red $=$ high citation percentile Blue $=$ low citation percentile

Leading country

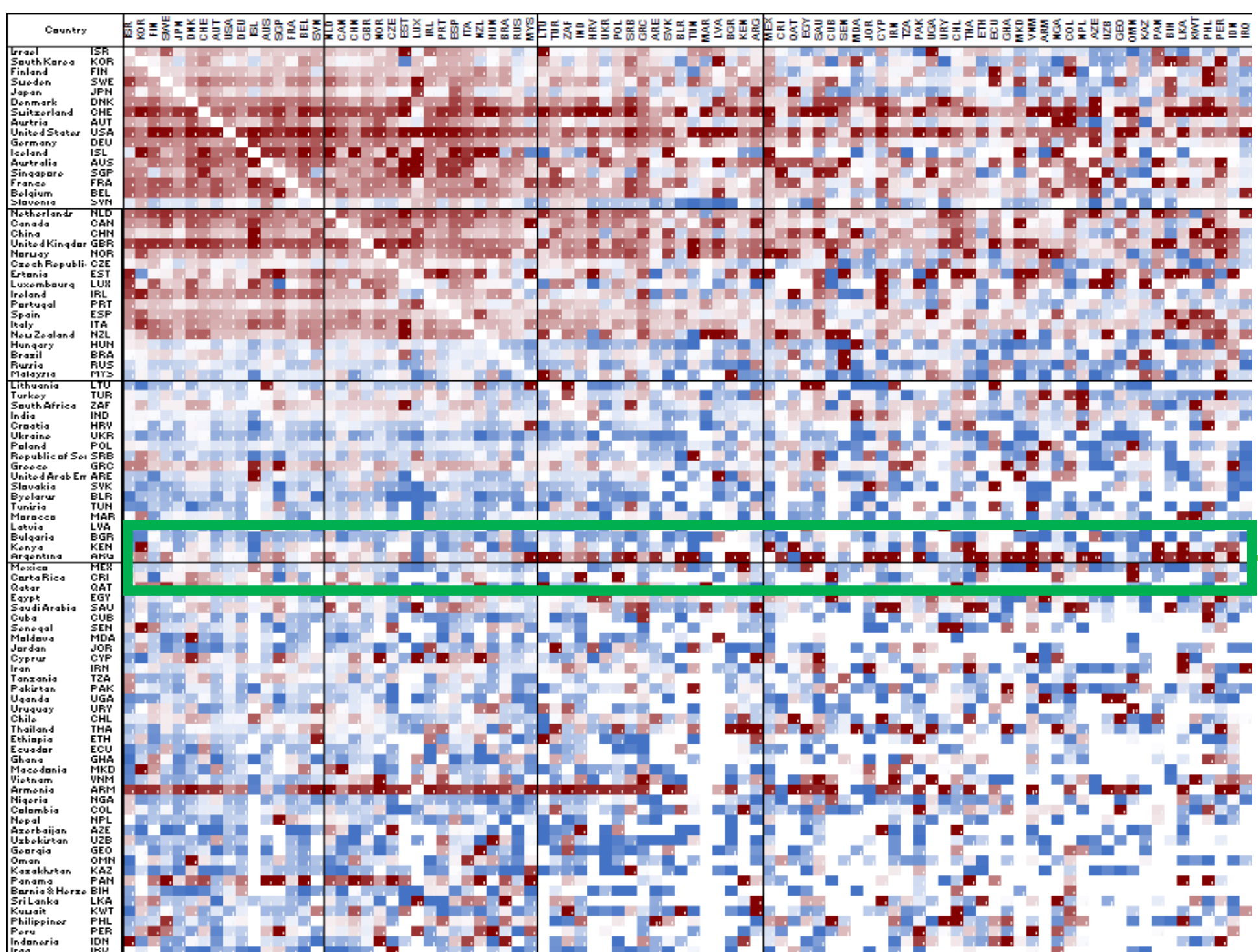

Argentina

A regional leader? 


\section{Summary of findings}




\section{Summary (1): Money Matters}

- The greater the research activity and investment, the more internalized the production

- But these countries likely to lead when they do collaborate

- Low-investment, low-activity nations are highly international, less likely to lead

Research and development expenditure (\% of GDP)

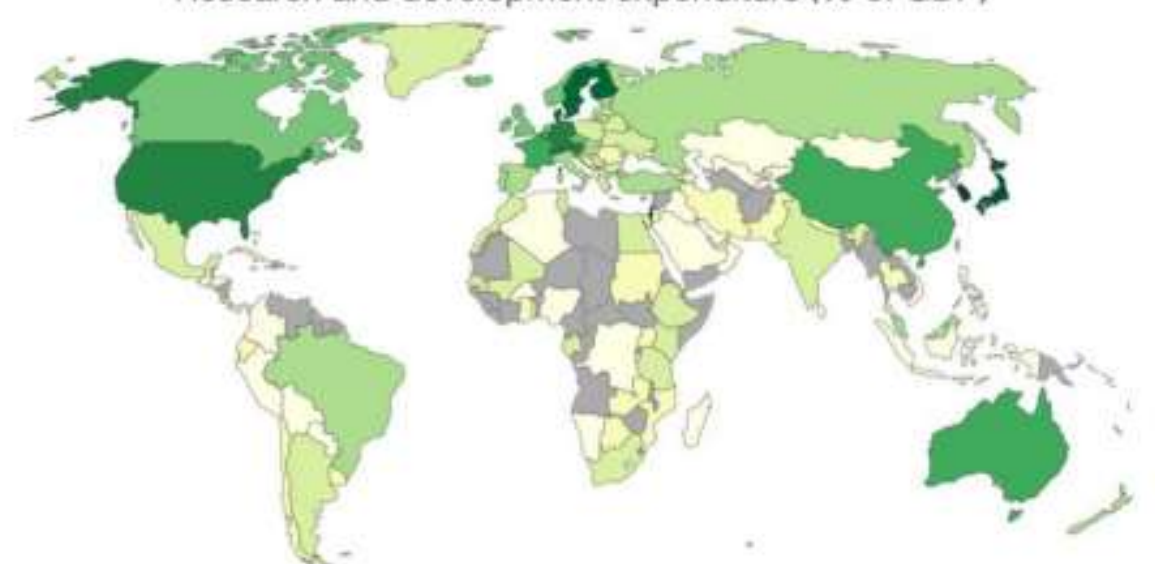

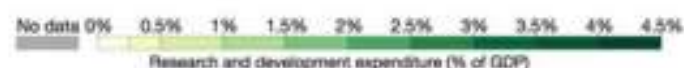




\section{Summary (2): Collaboration and leadership}

- International collaboration almost always has benefits to citations

- But leading on publications rarely offers much more benefit

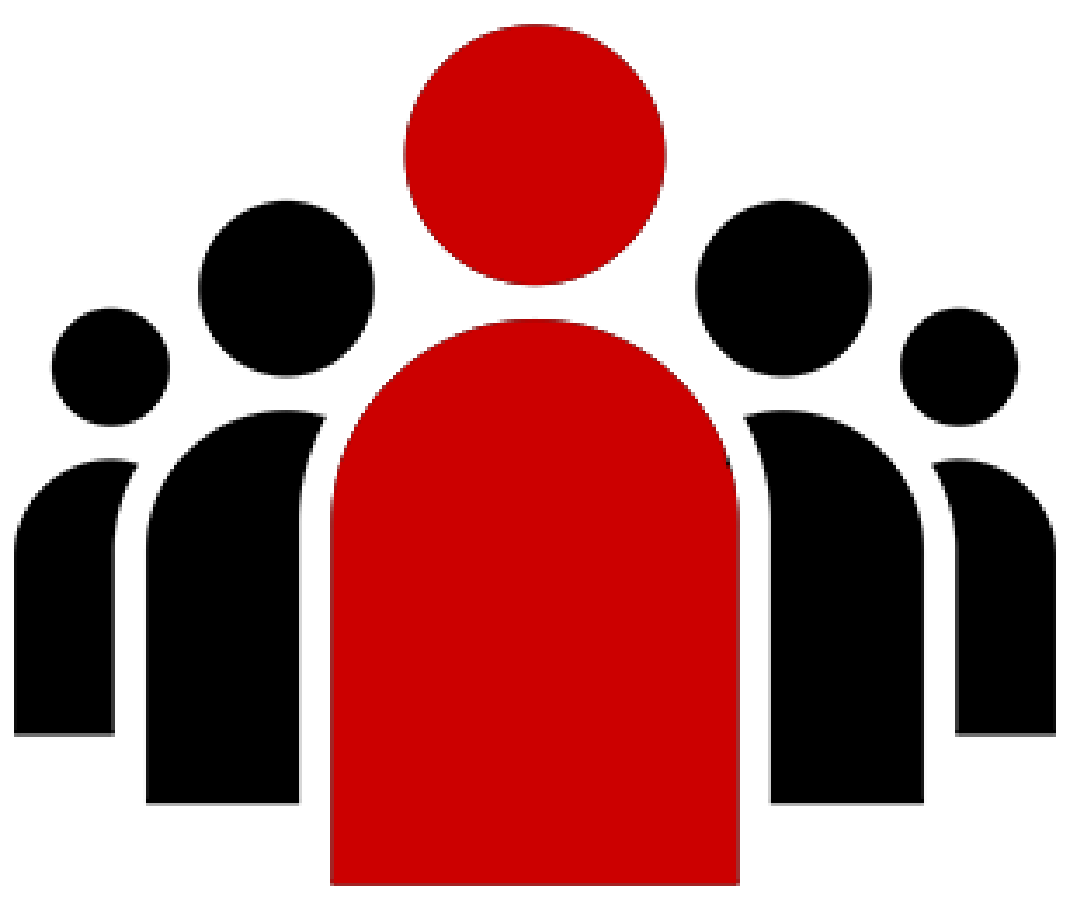


Summary (3): Not all partnerships are equal

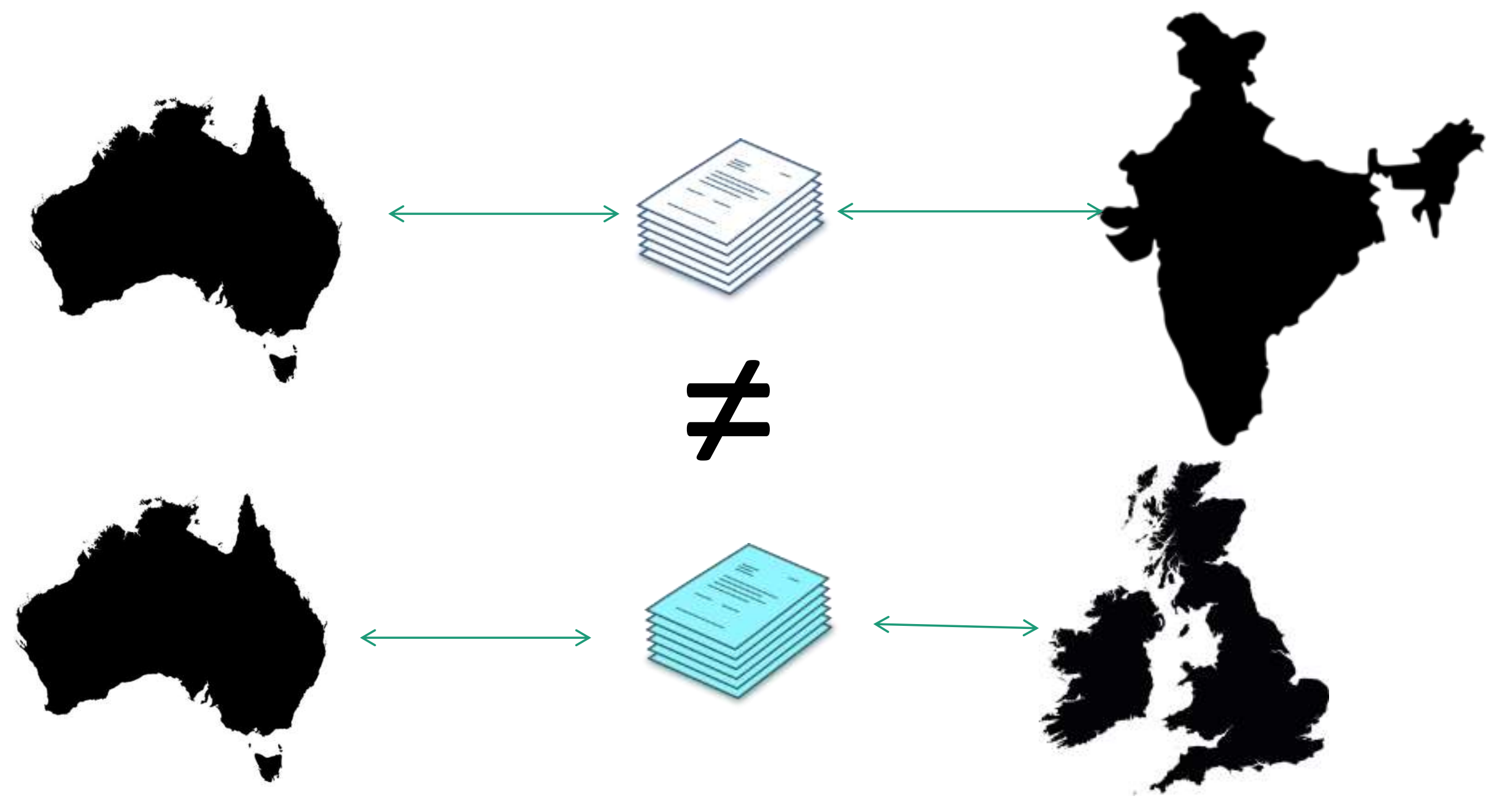




\section{Closing thoughts}


What detail do we lose with bibliometrics? 


\section{What about disciplinary specialization?}

Tropical Medicine

\author{
Experimental Physics
}

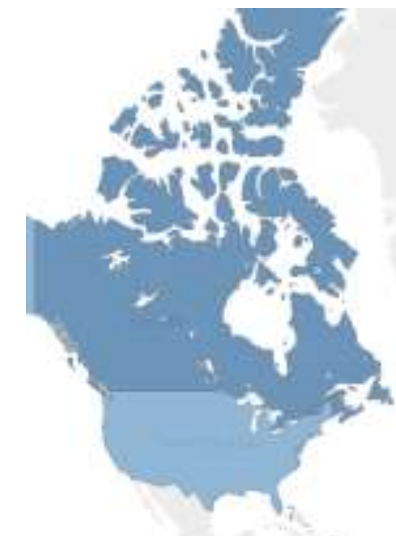




\section{Who sets the agenda?}

- "Following" leads to more citations

- Is the "periphery" able to set their own agenda and follow their own priorities?

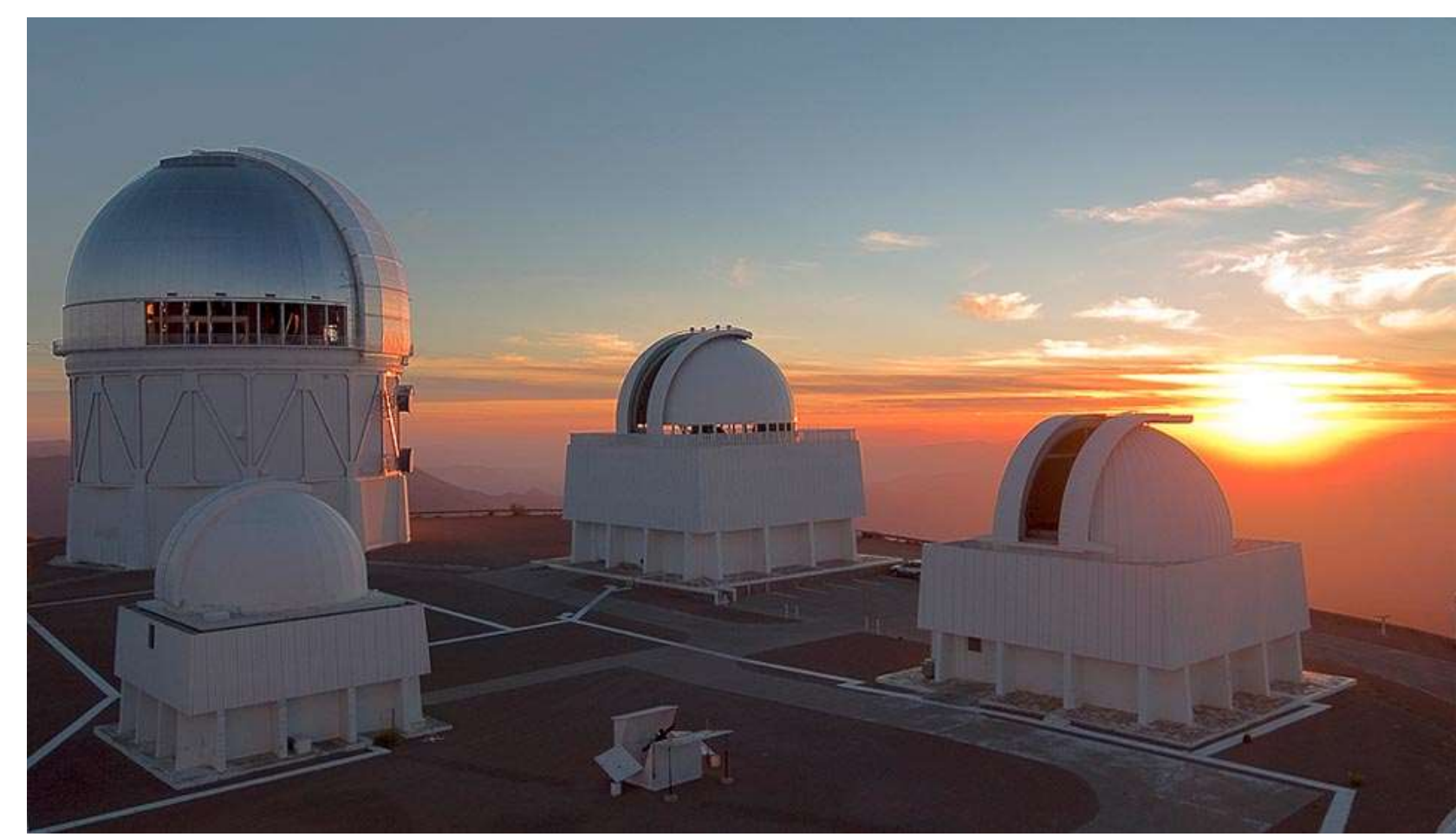


Thanks!

zaida.chinchilla@csic.es

Zaida Chinchilla-Rodríguez

Cassidy Sugimoto, Vincent Lariviére

Paper submitted to PLoS One

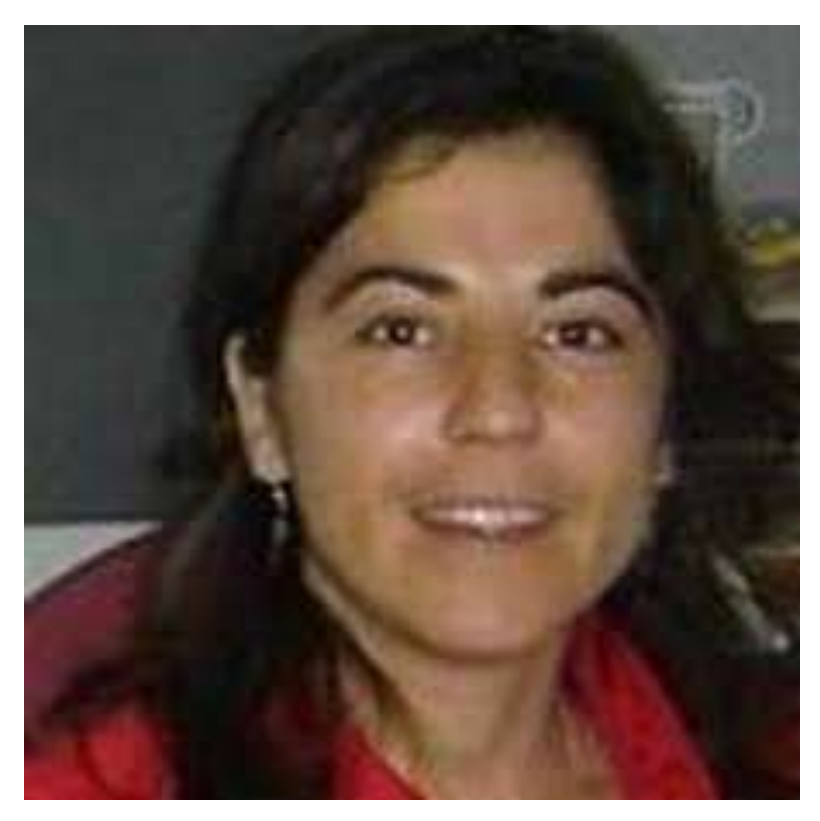

Seminarios del

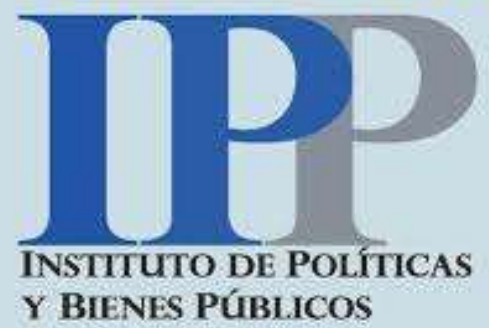

